\title{
REINTERPRETAÇÃO DO COMPLEXO INTRUSIVO LAVRAS DO SUL, RS, DE ACORDO COM OS SISTEMAS VULCANO-PLUTÔNICOS DE SUBSIDÊNCIA. PARTE 2: QUÍMICA MINERAL, GEOQUÍMICA E ISÓTOPOS DE Pb-Sr-Nd
}

\author{
MARIA DO CARMO GASTAL ${ }^{1}$ \& JEAN MICHEL LAFON²
}

\begin{abstract}
The post-collisional Lavras do Sul intrusive complex- LSIC, southern Brazil, is associated with basic-to-intermediate rocks derived from two lithospheric mantle segments. All rocks show a geochemical subduction signature, with negative $\mathrm{Nb}$ anomalies. Minettes occurring as dykes are potassic, alkalic rocks containing olivine $\left(\mathrm{F}_{091.86}\right), \mathrm{Cr}$-diopside and Ba-rich Ti-phlogopite, whose chemistry is only slightly modified by crustal processes. They are enriched in LREE, LILE and HFSE, and have high radiogenic isotopic ratios, so they derived from an enriched mantle previously modified in subduction events. We conclude that they register the change to an extensional regime that had occurred during the later magmatic LSIC-events. The others rocks are more evolved and have a shoshonitic composition, including trachyandesites, spessartites and the Arroio do Jacques monzodiorite $(\mathrm{AJM})$. They have augite as the main mafic phase, and variable trace elements and $\mathrm{Pb}-\mathrm{Sr}-\mathrm{Nd}$ isotopic ratios. They derived from the mantle wedge produced during Neoproterozoic orogenies, but with a more prominent role of open-system differentiation processes. The interaction with minette magma is proposed for AJM that has intermediate trace element contents and isotopic ratios. The two groups of LSIC-granitoids were similarly originated from two parental magmas. Most have a shoshonitic affiliation, including the Tapera monzonite-TM in the north, and the core facies of the southern body (granodiorite and hybrid granites). Alkaline granites (syenogranite and perthite granite) form semicircular stocks around this core. Contrasts in the emplacement depth of these rocks, revealed by Al-in amphibole geobarometer, imply in more than one cycle of subsidence-resurgence. Granites from the core, classified as low temperature I-type granites, had a major crustal contribution. They formed during the resurgence (4-2 kbar) at ca. $600 \mathrm{Ma}$. Alkaline granites were emplaced at shallow levels (minor or equal to $2 \mathrm{kbar}$ ) through successive episodes, between 598 and $586 \mathrm{Ma}$, that apparently affected the border of those from the core. They involved the interaction of two parental magmas, but with increasing contribution of the alkalic type.
\end{abstract}

Keywords: Post-collisional potassic rocks, Low-temperature granites, $\mathrm{Pb}-\mathrm{Sr}-\mathrm{Nd}$ isotopes, Igneous petrogenesis, Geochemistry, Mineral chemistry.

\begin{abstract}
Resumo O complexo intrusivo Lavras do Sul-CILS, RS, congrega intrusões pós-colisionais associadas a rochas básico-intermediárias derivadas de dois segmentos do manto litosférico. Todas estas rochas exibem a assinatura da subducção com anomalias negativas de $\mathrm{Nb}$. Minetes, que ocorrem como diques, são rochas alcalinas potássicas contendo olivina $\left(\mathrm{F}_{091-86}\right)$, Cr-diopsídio e Ti-flogopita rica em $\mathrm{Ba}$, cuja composição química evidencia pouca modificação em processos crustais. Estas rochas são ricas em ETRL, LILE e HFSE, e exibem razões isotópicas mais radiogênicas, de modo que são derivadas do manto rico em elementos incompatíveis, modificado em eventos prévios de subducção. E possível concluir que os minetes registram a mudança para regime extensional ocorrida durante o final dos eventos ígneos no CILS. As demais são rochas mais diferenciadas de filiação shoshonítica, que incluem lavas traquiandesíticas, o monzodiorito Arroio do Jacques (MAJ), e espessartitos subordinados. Estas contêm augita como principal máfico, e exibem razões isotópicas e conteúdo de elementos traços variáveis. Derivaram de cunha do manto produzida durante o Neoproterozóico, porém com maior participação de processos de diferenciação em sistema aberto. O MAJ, que exibe valores intermediários de elementos traços e razões isotópicas, envolveu também a interação com o magma minete. Os dois grupos de granitóides do CILS derivaram de magmas parentais análogos. A maioria tem filiação shoshonítica, e inclui o monzonito Tapera no norte e os granitos do núcleo a sul (granodiorito e granitos híbridos). Contrastes nas profundidades de colocação destes, reveladas pelo geobarômetro do $\mathrm{Al}$, no anfibólio, sugerem mais de um ciclo de subsidência-ressurgência. Os granitos do núcleo foram formados durante a ressurgência (4-2 kbar) em evento próximo a $600 \mathrm{Ma}$. São classificados como granitos do tipo I de baixa temperatura, e tiveram importante contribuição crustal. Os termos alcalinos (sienogranito e pertita granito) ocorrem em corpos semicirculares periféricos e foram posicionados, em níveis rasos (menor ou igual a $2 \mathrm{kbar}$ ), em pulsos sucessivos entre 598 a 586 $\mathrm{Ma}$, tendo afetado a borda das fácies do núcleo. Estes também envolveram a interação dos dois magmas parentais, porém com maior participação daquele de natureza alcalina.
\end{abstract}

Palavras-chave: Rochas potássicas pós-colisionais, Granitos de baixa temperatura, Isótopos de $\mathrm{Pb}-\mathrm{Sr}-\mathrm{Nd}$, Petrogênese ígnea, Geoquímica, Química mineral.

\begin{abstract}
INTRODUÇÃO
Os dados geocronológicos, geológicos e geofísicos, discutidos na primeira parte (Gastal et al. 2006a), evidenciam que os granitóides do complexo intrusivo Lavras do Sul - CILS representam intrusões agregadas de um sistema vulcano-plutônico de subsidência. No norte, está o monzonito Tapera (MT) e o setor sul consiste no corpo granítico circundado a norte-nordeste pelo monzodiorito Arroio do Jacques (MAJ). Os granitos constituem intrusão centrada com zonalidade reversa. Granodiorito e granitos híbridos, posicionados no núcleo, são circundados por sienogranito e pertita granito de afinidade alcalina. O MAJ parece vinculado ao MT, porém sua filiação geoquí-
\end{abstract}

mica é particular, assemelhando-se ora às rochas shoshoníticas (Gastal 1998), ora as alcalinas saturadas em sílica (Lima 1995). A composição dos diques acompanha a evolução das unidades no CILS. Enquanto rochas intermediárias predominam no setor norte, no corpo granítico são bimodais, incluindo dacito-riolito e minetes. As idades ${ }^{206} \mathrm{~Pb} /{ }^{238} \mathrm{U}$ evidenciam a natureza multi-intrusiva dos granitos, porém a formação do arcabouço do complexo intrusivo ocorreu em um curto período, de 603 a $597 \mathrm{Ma}$, e o pertita granito é mais jovem $(586,0 \pm 2,8 \mathrm{Ma})$.

São discutidos, nesta parte, os aspectos petrológicos de rochas associadas à formação do CILS. Além da revisão da lite- 
ratura, são apresentados novos dados de química mineral (fases máficas e acessórias), geoquímicos e isótopos de $\mathrm{Pb}-\mathrm{Nd}$-Sr para estas rochas, os quais são comparados aos de vulcânicas (Formação Hilário). A discussão é direcionada a duas questões centrais: (a) caracterização de magmas parentais de derivação mantélica, com base no estudo comparativo entre o MAJ, minetes e as rochas intermediárias da Formação Hilário; e (b) discriminação de granitóides com afinidades contrastantes. São também incluídos dados geoquímicos e mineralógicos do granito Estrela (GE), correlacionado aos tipos alcalinos do CILS.

\section{UNIDADES PLUTÔNICAS E SUBVULCÂNICAS DO COMPLEXO INTRUSIVO, E VULCÂNICAS CORRELA-}

TAS As características geológicas e petrográficas das unidades do CILS, mostradas na figura 1, são discutidas em Gastal et al. (2006a). Para a sequiência vulcânica cronocorrelata, os dados mineralógicos e litogeoquímicos são de Lima (1995). A unidade efusiva basal, situada à sudeste do CILS, é composta por traquiandesito basáltico-TAB, com fenocristais de olivina (Ol) e Mg-augi-

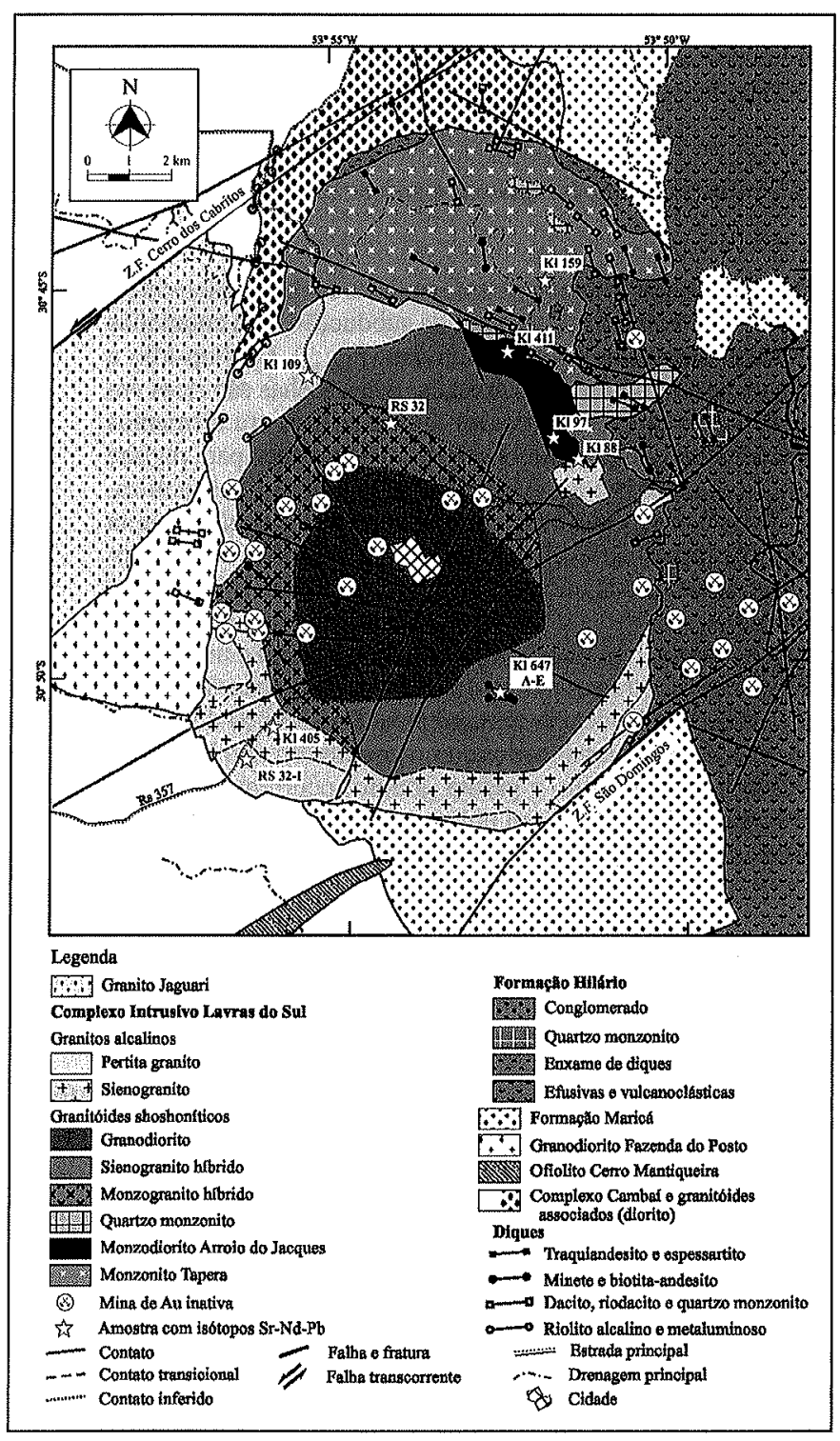

Figura 1 - Mapa geológico do complexo intrusivo Lavras do Sul - CILS, com a localização de amostras com dados de isótopos de Pb-Nd-Sr. Amostras RS-32 e RS 32-I segundo Babinski et al. (1996). ta e matriz hemicristalina. As outras quatro unidades (numeradas de 1 a 4, da base para o topo), constituídas por traquiandesito, contém fenocristais de plagioclásio ( $\mathrm{Pl}$ ) e de Mg-augita imersos em matriz microcristalina. $O$ espessartito é composto de fenocristais médios de $\mathrm{Mg}$-hastingsita e Mg-augita, e matriz fina a base de andesina-oligoclásio e Mg-hastingsita (Lima \& Nardi 1991). Os monzonitos regionais, discutidos por Lima (1995), incluem amostras do MT e de quartzo monzonitos associados. Os últimos formam também corpos menores, intrusivos na seqüência vulcânica à nordeste-leste do CILS. Para estes manteve-se o posicionamento estratigráfico proposto por Porcher \& Lopes (2000), de modo que são referidos na figura 1 como da Formação Hilário. Os dados químicos (rocha e minerais) para os monzonitos são utilizados sem distinção, uma vez que não se dispõem da localização precisa das amostras estudadas por Lima (1995). A similaridade na petrografia e relações de campo entre os dois tipos (MT e quartzo monzonitos), como discute Liz (2003), referenda esta postura. Para uma amostra do MT, são apresentados dados químicos de anfibólio e isótopos de $\mathrm{Pb}$.

Química mineral Análises químicas representativas de fases máficas e acessórias das principais intrusivas do CILS e minetes, incluindo arfevdsonitas do GE (Gastal 1998), são apresentadas na tabela 1. Condições de análise detalhadas em Gastal (2004).

MINETES No ol-minete, a Ol cognata possui conteúdo elevado de Fo e NiO, e baixo de $\mathrm{CaO}$ e $\mathrm{MnO}$ (Tab. 1), e a diferenciação é marcada por decréscimo de $\mathrm{NiO}$ para pequeno declínio de Fo (91-86\%). Mg-cromita aluminosa ocorre em micro-inclusões no centro e borda de fenocristais de $\mathrm{Ol}$, e ocasionalmente diopsídio (Di). Na matriz, a Mg-cromita é rara, exibindo forte zonação para Ti-magnetita $\left(\mathrm{Usp}_{54-49}\right)$ rica em Mg e Cr (Tab. 1). A relação entre Cr-espinélio e Ol sugere que o primeiro é anterior na cristalização, indicando $f \mathrm{O}_{2}$ similar ou superior ao oxy-buffer NNO (Hill \& Roeder 1974). Nos dois tipos de minete, os componentes quadrilaterais do Di não variam muito (Fig. 2A) e o $m g$ $\left(\mathrm{Mg} /\left(\mathrm{Mg}+\mathrm{Fe}^{+2}\right)^{*} 100\right.$, em a.u.f.) neste, de $91-86 \%$, é equiparável ao da Ol. $\mathrm{Al}_{2} \mathrm{O}_{3}$ e $\mathrm{SiO}_{2}$ definem trends paralelos com maiores valores no minete (Fig. 2C), sugerindo magma subsaturado em sílica e mais alcalino (Deer et al. 1978). $\mathrm{Cr}_{2} \mathrm{O}_{3}$ é mais alto no $\mathrm{Di}$ do minete, e $\mathrm{TiO}_{2}$ no do ol-minete, de modo que as razões ${ }^{\mathrm{VI}} \mathrm{Al} /$ ${ }^{\mathrm{IV}} \mathrm{Al}$ mais elevadas no primeiro são consistentes com equilíbrio a maior pressão (Fig. 2B). A Ti-flogopita, com $m g$ de $86-70 \%$, possuí conteúdo elevado de $\mathrm{Ba}$ e moderado de $\mathrm{Al}_{2} \mathrm{O}_{3}(>14 \%)$. No minete, esta exibe composição variada, com maior $\mathrm{Mg}$ e Al (Tab. 1). A reversão na razão $\mathrm{Fe} / \mathrm{Mg}$ e o decréscimo de $\mathrm{TiO}_{2}$ no núcleo de fenocristais de Ti-flogopita parece traduzir a recarga com magma primitivo. No ol-minete, a mica é deficiente em ${ }^{\mathrm{IV}} \mathrm{Al}$ e exibe maior $\mathrm{TiO}_{2}$ e $\mathrm{BaO}$, consistente com a natureza tardia e cristalização a menor pressão (Righter \& Carmichael 1996). Fe-biotita na matriz do vogesito e anfibólio do minete/vogesito exibem composição contrastante com $m g$, respectivamente, de 48 e $16 \%$ (Fig. 2D) e $57-27 \%$ (Tab. 1). No último, a razão $\mathrm{SiO}_{2} / \mathrm{Al}_{2} \mathrm{O}_{3}$ varia pouco para amplo intervalo de $\mathrm{FeO}, \mathrm{MgO}$ e $\mathrm{TiO}_{2}$, definindo trend similar ao do anfibólio de diferenciados hidratados de basaltos alcalinos (Mitchell 1990). Comparado ao anfibólio do minete, o do vogesito possui maior $\mathrm{TiO}_{2}$ (Fig. 2E) $\mathrm{e}^{\mathrm{M} 4} \mathrm{Ca}$ (Fig. 3A). Em ambos, o decréscimo de $\mathrm{TiO}_{2}$ é paralelo ao aumento de $\mathrm{FeO}^{*}\left(=\mathrm{FeO}_{1} /\left(\mathrm{FeO}_{\mathrm{t}}+\mathrm{MgO}\right)\right)$ e $\mathrm{Fe}_{2} \mathrm{O}_{3}$, consistente com cristalização a moderada $\mathrm{fO}_{2}$. Nesse sentido, ocorre o aumento de $\mathrm{Al}_{\mathrm{t}}$ e $\mathrm{Fe} /(\mathrm{Mg}+\mathrm{Fe}$ ) (Fig. 3B). Tais variações parecem refletir a interação de magmas distintos, uma vez que ocorrem na mesma amostra.

TRAQUIANDESITOS E ESPESSARTITO Nas vulcânicas, a Ol é mais ferrosa ( $m$ g de $68,0-62,5 \%)$, com maior $\mathrm{MnO}(0,24$ - 


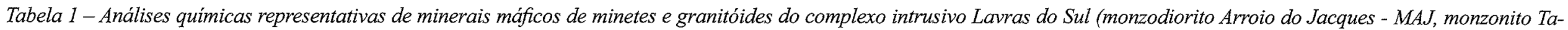
pera-MT), e do granito Estrela-GE.

\begin{tabular}{|c|c|c|c|c|c|c|c|c|c|c|c|c|c|c|c|c|c|c|c|}
\hline & \multicolumn{2}{|c|}{ Olivina } & \multicolumn{7}{|c|}{ Diopsídio } & \multicolumn{3}{|c|}{ Mg-augita } & \multicolumn{2}{|c|}{ Fe-enstatita } & \multicolumn{5}{|c|}{ Anfibólio } \\
\hline & $\begin{array}{c}647-02 \\
F\end{array}$ & $\begin{array}{c}\text { 647-O9 } \\
\text { MF }\end{array}$ & $\begin{array}{c}7 \mathrm{C}-20 \\
\mathrm{MF} \\
\end{array}$ & $\begin{array}{c}7 \mathrm{C}-22 \\
\mathrm{MF}\end{array}$ & $\begin{array}{c}\text { C47-1 } \\
\text { ma }\end{array}$ & $\begin{array}{c}7 \mathrm{C}-14 \\
\mathrm{ma}\end{array}$ & $\begin{array}{c}647-1 \\
F \\
\end{array}$ & $\begin{array}{c}647-4 \\
\mathrm{MF}\end{array}$ & $\begin{array}{c}7 \mathrm{C}-27 \\
\mathrm{MF}\end{array}$ & C419-29 & C419-1 & C417-3 & C419-26 & C419-10 & $\begin{array}{c}\text { A47-2 } \\
\text { ma }\end{array}$ & $\begin{array}{c}647 \mathrm{~A}-4 \\
\mathrm{MF}\end{array}$ & $\begin{array}{c}647 \mathrm{~A}-5 \\
\mathrm{MF}\end{array}$ & $\begin{array}{c}\text { A647-4 } \\
\text { ma }\end{array}$ & $\begin{array}{c}\text { A417-20 } \\
\text { corona }\end{array}$ \\
\hline $\mathrm{SiO}_{2}$ & 41,76 & 41,35 & 53,32 & 51,21 & 53,16 & 51,43 & 52,15 & 51,72 & 51,61 & 53,65 & 52,45 & 53,18 & 53,69 & 53,99 & 37,52 & 38,93 & 37,48 & 37,85 & 51,24 \\
\hline $\mathrm{TiO}_{2}$ & 0,02 & n.d. & 0,80 & 1,19 & 0,81 & 0,82 & 0,74 & 0,87 & 1,11 & 0,32 & 0,71 & 0,33 & 0,14 & 0,17 & 2,73 & 4,77 & 3,02 & 4,41 & 1,03 \\
\hline $\mathrm{Al}_{2} \mathrm{O}_{3}$ & 0,08 & 0,07 & 2,35 & 4,11 & 2,28 & 3,62 & 4,13 & 4,12 & 4,20 & 0,74 & 1,73 & 1,97 & 1,07 & 0,34 & 14,48 & 12,92 & 14,35 & 13,56 & 4,85 \\
\hline $\mathrm{Cr}_{2} \mathrm{O}_{3}$ & 0,05 & 0,08 & 0,84 & 1,39 & 0,47 & 1,13 & 1,50 & 1,07 & 0,26 & 0,16 & 0,37 & 0,28 & 0,31 & 0,06 & n.a. & n.d. & n.d. & n.d. & n.a. \\
\hline $\mathrm{Fe}_{2} \mathrm{O}_{3}$ & 0 & 0 & 0 & 1,55 & 0 & 1,27 & 0 & 0 & 2,36 & 0 & 0 & 0 & 0 & 0 & 1,97 & 2,03 & 1,02 & 0,43 & 2,57 \\
\hline $\mathrm{FeO}$ & 8,85 & 11,68 & 4,12 & 2,95 & 4,98 & 3,17 & 3,69 & 4,52 & 3,25 & 9,65 & 10,03 & 8,81 & 20,93 & 22,53 & 17,44 & 13,94 & 21,20 & 19,50 & 10,20 \\
\hline $\mathrm{MnO}$ & 0,07 & 0,15 & 0,12 & 0,09 & 0,14 & 0,05 & 0,12 & 0,07 & 0,06 & 0,17 & 0,24 & 0,18 & 0,28 & 0,28 & 0,29 & 0,19 & 0,31 & 0,23 & 0,24 \\
\hline $\mathrm{NiO}$ & 0,34 & 0,26 & 0,03 & n.d. & 0,03 & 0,02 & 0,08 & 0,01 & 0,13 & ก.a. & n.a. & n.a. & n.a. & n.a. & n.a. & n.a. & n.a. & n.a. & n.a. \\
\hline $\mathrm{MgO}$ & 49,89 & 47,54 & 16,67 & 15,75 & 16,60 & 16,10 & 15,40 & 15,03 & 15,83 & 14,09 & 13,88 & 14,11 & 22,62 & 22,36 & 6,94 & 10,54 & 5,09 & 6,81 & 15,74 \\
\hline $\mathrm{CaO}$ & 0,23 & 0,18 & 22,20 & 22,83 & 21,74 & 22,13 & 21,97 & 22,59 & 22,59 & 21,81 & 20,22 & 21,25 & 1,35 & 0,89 & 11,41 & 11,92 & 11,58 & 11,81 & 11,80 \\
\hline $\mathrm{Na}_{2} \mathrm{O}$ & n.d. & n.d. & 0,31 & 0,41 & 0,33 & 0,43 & 0,45 & 0,38 & 0,43 & 0,19 & 0,21 & 0,27 & n.d. & 0,05 & 2,16 & 2,03 & 1,88 & 1,78 & 0,91 \\
\hline $\mathrm{K}_{2} \mathrm{O}$ & 0,01 & n.d. & 0,02 & 0,02 & 0,02 & 0,01 & 0,01 & 0,01 & 0,07 & n.d. & n.d. & 0,02 & n.d. & n.d. & 1,42 & 1,78 & 1,62 & 1,59 & 0,50 \\
\hline $\mathrm{F}$ & - & -- & - & -- & -- & -. & - & - & ... & -- & - & -- & -- & - & 0,61 & 0,20 & 0,34 & 0,63 & 0,28 \\
\hline $\mathrm{Cl}$ & .- & -- & -- & .- & -- & - & -_. & -- & - & -- & -- & -- & -- & - & 0,01 & 0,02 & n.d. & 0,05 & 0,03 \\
\hline $\mathrm{F}, \mathrm{Cl} \equiv \mathrm{O}$ & - & -- & -- & - & -- & -- & - & -- & -- & - & - & -- & -. & - & 0,26 & 0,09 & 0,14 & 0,28 & 0,12 \\
\hline Total & 101,30 & 101,31 & 100,78 & 101,49 & 100,56 & 100,19 & 100,24 & 100,39 & 101,90 & 100,78 & 99,84 & 100,40 & 100,39 & 100,67 & 96,72 & 99,18 & 97,75 & 98,37 & 99,27 \\
\hline $\mathrm{FeO}_{t}$ & 8,85 & 11,68 & 4,12 & 4,34 & 4,98 & 4,32 & 3,69 & 4,52 & 5,37 & 9,65 & 10,03 & 8,81 & 20,93 & 22,53 & 19,21 & 15,77 & 22,12 & 19,89 & 12,52 \\
\hline $\mathrm{Fa}$ & 9,04 & 12,10 & -- & -. & -- & -- & -- & - & - & -- & - & -.. & -- & - & - & -- & -- & - & - \\
\hline Wo & - & - & 45,52 & 47,35 & 44,54 & 46,14 & 47,39 & 48,00 & 46,21 & 44,46 & 42,49 & 44,35 & 2,71 & 1,77 & - & - & -- & - & - \\
\hline En & -- & -- & 47,62 & 45,48 & 47,32 & 46,73 & 46,18 & 44,42 & 45,10 & 39,95 & 40,61 & 40,99 & 63,75 & 62,47 & -- & - &.- & -. & \\
\hline Fs & -- & -. & 6,81 & 7,17 & 8,14 & 7,13 & 6,44 & 7,58 & 8,69 & 15,59 & 16,90 & 14,66 & 33,54 & 35,76 & -. & - & -- & -. & - \\
\hline $\mathrm{Jd}+\mathrm{Ae}$ & - & - & 2,28 & 3,08 & 2,36 & 3,13 & 3,41 & 2,85 & 3,19 & 1,42 & 1,55 & 1,96 & - & 0,40 & -- & - & -- & -- & -- \\
\hline$m g(\mathrm{Fo})$ & 90,96 & 87,90 & 87,83 & 90,52 & 85,65 & 90,05 & 88,13 & 85,59 & 89,67 & 72,26 & 71,13 & 74,07 & 65,84 & 63,89 & 41,50 & 57,40 & 29,95 & 38,36 & 73,33 \\
\hline${ }^{\mathrm{VI}} \mathrm{Al} /{ }^{\mathrm{N}} \mathrm{Al}$ & - & -- & 0,56 & 0,20 & 0,53 & 0,30 & 0,91 & 0,66 & 0,28 & 2,20 & 1,30 & 2,19 & 2,07 & 14,00 & - & - & -- & - & - \\
\hline $\mathrm{IAG}$ & - &.- & - & - & - & - & - & -. & -- & -- & - & -- & - & -- & 0,35 & 0,41 & 0,34 & 0,34 & 0,42 \\
\hline
\end{tabular}

Amostras - olivina minete: 647-02, 647-09, 7C-20, 7C-22, C47-1 e 7C-14; minete: 647-1, 647-4, 7C-27, A47-2 (Fe-pargasita); vogesito: 647A-4 (kaersutita), 647A-5 (Fe-pargasita), 647A-4 (Fe-kaersutita) e A647-3 (Fepargasita); Monzodiorito Arroio do Jacques: C419-29, C419-1, C417-3, C419-26, C419-10, e A417-20 (Mg-homblenda). 
Tabela 1 - continuação: anfibólios e Fe-Mg micas

\begin{tabular}{|c|c|c|c|c|c|c|c|c|c|c|c|c|c|c|c|c|c|c|}
\hline & $\begin{array}{c}\text { A417-11 } \\
\text { I }\end{array}$ & $\begin{array}{l}\text { 159-A5 } \\
\mathrm{P}(\mathrm{c})\end{array}$ & $\begin{array}{c}\text { 159-A6 } \\
P(b)\end{array}$ & $\begin{array}{c}\text { 681A-3 } \\
\mathrm{T} \\
\end{array}$ & $\begin{array}{c}666 \mathrm{~A}-5 \\
\mathrm{I} \\
\end{array}$ & $\begin{array}{c}98 \mathrm{~A}-19 \\
\mathrm{P}\end{array}$ & $\begin{array}{c}672 \mathrm{~A}-20 \\
\mathrm{P} \\
\end{array}$ & $\begin{array}{c}672 \mathrm{~A}-26 \\
\mathrm{~T} \\
\end{array}$ & $\begin{array}{c}\text { A405-21 } \\
\mathrm{T} \\
\end{array}$ & $\begin{array}{c}\text { A405-28 } \\
\text { I }\end{array}$ & $\begin{array}{c}\text { A109-8 } \\
T \\
\end{array}$ & $\begin{array}{c}\text { A14-5 } \\
\text { I }\end{array}$ & $\begin{array}{c}\text { A399-4 } \\
T\end{array}$ & $\begin{array}{c}511 C \\
\text { I }\end{array}$ & $\begin{array}{c}\mathbf{5 1 1 F} \\
\text { I }\end{array}$ & $\begin{array}{l}7 F-4 \\
\text { MF }\end{array}$ & $\begin{array}{c}7 \mathrm{~F}-5 \\
\mathrm{ma}\end{array}$ & $\begin{array}{c}\text { 647B-1 } \\
F(c)\end{array}$ \\
\hline $\mathrm{SiO}_{2}$ & 51,53 & 44,46 & 47,03 & 44,24 & 45,41 & 45,55 & 45,92 & 42,97 & 45,19 & 43,15 & 43,12 & 44,48 & 46,45 & 49,80 & 50,45 & 35,89 & 34,74 & 37,92 \\
\hline $\mathrm{TiO}_{2}$ & 0,90 & 2,08 & 1,36 & 1,56 & 1,06 & 1,54 & 1,15 & 1,89 & 1,37 & 1,02 & 1,32 & 1,09 & 1,32 & 1,47 & 1,42 & 7,81 & 8,73 & 4,94 \\
\hline $\mathrm{Al}_{2} \mathrm{O}_{3}$ & 4,78 & 9,43 & 6,19 & 7,93 & 7,08 & 6,09 & 6,32 & 8,49 & 5,64 & 6,76 & 6,42 & 4,10 & 3,21 & 1,21 & 0,78 & 15,04 & 15,09 & 15,48 \\
\hline $\mathrm{Fe}_{2} \mathrm{O}_{3}$ & 3,15 & 2,61 & 3,08 & 3,93 & 4,77 & 3,57 & 3,93 & 3,47 & 4,32 & 3,67 & 7,49 & 6,81 & 7,16 & 5,28 & 9,60 & 0,53 & 0,03 & 0,60 \\
\hline $\mathrm{FeO}$ & 9,91 & 15,18 & 13,57 & 16,91 & 16,55 & 18,29 & 16,90 & 18,62 & 21,44 & 22,25 & 21,84 & 25,78 & 25,93 & 28,40 & 25,15 & 10,93 & 10,40 & 9,15 \\
\hline $\mathrm{MnO}$ & 0,21 & 0,45 & 0,44 & 0,58 & 0,63 & 0,55 & 0,38 & 0,58 & 0,61 & 0,52 & 0,73 & 1,09 & 0,71 & 0,92 & 0,73 & 0,10 & n.d. & 0,08 \\
\hline MgO & 15,45 & 9,88 & 11,25 & 8,83 & 9,06 & 8,32 & 9,24 & 7,72 & 6,25 & 5,60 & 4,77 & 2,52 & 2,62 & 0,12 & 0,04 & 15,38 & 15,18 & 17,70 \\
\hline $\mathrm{BaO}$ & n.a & n.a. & n.a. & n.a & n.a & n.a & n.a & n.a & n.a & n.a & n.a & n.a & n.a & n.a & n.a & 0,82 & 1,48 & 1,28 \\
\hline $\mathrm{CaO}$ & 11,08 & 10,88 & 10,93 & 11,18 & 11,07 & 10,55 & 10,69 & 11,17 & 9,93 & 10,43 & 10,30 & 9,19 & 8,09 & 0,93 & 0,53 & 0,09 & 0,09 & 0,09 \\
\hline $\mathrm{Na}_{2} \mathrm{O}$ & 1,01 & 1,91 & 1,30 & 1,55 & 1,42 & 1,61 & 1,58 & 1,67 & 2,07 & 1,82 & 1,69 & 1,76 & 2,19 & 6,99 & 7,03 & 0,40 & 0,47 & 0,67 \\
\hline $\mathrm{K}_{2} \mathrm{O}$ & 0,43 & 1,22 & 0,71 & 0,93 & 0,95 & 0,85 & 0,93 & 1,04 & 0,87 & 1,19 & 1,09 & 1,00 & 1,00 & 1,24 & 1,10 & 8,83 & 8,50 & 9,08 \\
\hline $\mathrm{F}$ & 0,04 & 0,34 & 0,32 & 0,47 & 0,38 & 0,38 & 0,55 & 0,63 & 0,05 & 0,73 & 0,54 & 0,13 & 0,75 & 0,79 & 0,74 & 1,37 & 0,07 & n.d. \\
\hline $\mathrm{Cl}$ & 0,04 & 0,07 & 0,03 & 0,07 & 0,13 & 0,18 & 0,19 & 0,20 & 0,14 & 0,25 & 0,25 & 0,12 & 0,09 & 0,05 & 0,03 & n.d. & 0,01 & 0,01 \\
\hline $\mathrm{F}, \mathrm{Cl} \equiv \mathrm{O}$ & 0,03 & 0,17 & 0,14 & 0,21 & 0,19 & 0,20 & 0,27 & 0,31 & 0,05 & 0,36 & 0,28 & 0,08 & 0,34 & 0,34 & 0,32 & 0,58 & 0,03 & 0 \\
\hline Total & 98,50 & 98,34 & 96,05 & 97,97 & 98,32 & 97,28 & 97,50 & 98,14 & 97,82 & 97,03 & 99,28 & 97,99 & 99,18 & 96,85 & 97,28 & 96,61 & 94,76 & 97,00 \\
\hline $\mathrm{FeO}_{\mathrm{t}}$ & 12,74 & 17,53 & 16,34 & 20,45 & 20,84 & 21,50 & 20,43 & 21,74 & 25,32 & 25,55 & 28,58 & 31,91 & 32,37 & 33,15 & 33,79 & 11,41 & 10,43 & 9,69 \\
\hline$m g$ & 73,54 & 53,69 & 59,64 & 48,70 & 49,94 & 45,21 & 49,86 & 42,84 & 34,58 & 31,27 & 28,02 & 15,10 & 15.55 & 0,75 & 0,28 & 71,49 & 72,22 & 77,60 \\
\hline \multirow[t]{2}{*}{ LAG } & 0,44 & 0,47 & 0,47 & 0,45 & 0,48 & 0,52 & 0,57 & 0,46 & 0,77 & 0,63 & 0,62 & 0,99 & 1,59 & 10,61 & 16,35 & 0,44 & 0,66 & 0,71 \\
\hline & $\begin{array}{c}\text { 647B-2 } \\
\text { F (i) }\end{array}$ & $\begin{array}{c}\text { 647B-3 } \\
F(b)\end{array}$ & $\begin{array}{l}647 \mathrm{~B}-4 \\
\mathrm{MF}(\mathrm{c}) \\
\end{array}$ & $\begin{array}{l}647 \mathrm{~B}-5 \\
\text { MF (b) }\end{array}$ & $\begin{array}{c}\text { B419-6 } \\
T\end{array}$ & $\begin{array}{c}\text { B417-1 } \\
P\end{array}$ & $\begin{array}{c}\text { 681B-11 } \\
\text { P }\end{array}$ & $\begin{array}{c}\text { B642-10 } \\
P\end{array}$ & $\begin{array}{c}\text { B666-27 } \\
T\end{array}$ & $\begin{array}{c}\text { B98-5 } \\
P\end{array}$ & $\begin{array}{c}\text { 672B-7 } \\
P\end{array}$ & $\begin{array}{c}\text { 672B-6 } \\
T\end{array}$ & $\begin{array}{c}\text { B405-15 } \\
T\end{array}$ & $\begin{array}{c}\text { B405-23 } \\
\text { I }\end{array}$ & $\begin{array}{c}\text { B109-8 } \\
\text { I }\end{array}$ & $\begin{array}{c}\text { B110-71 } \\
T\end{array}$ & $\begin{array}{c}\text { B399-28 } \\
\text { I }\end{array}$ & $\begin{array}{c}\text { B399-21 } \\
\text { subsol. }\end{array}$ \\
\hline $\mathrm{SiO}_{2}$ & 38,59 & 35,40 & 37,57 & 35,93 & 39,41 & 37,24 & 36,71 & 35,79 & 36,18 & 36,33 & 36,81 & 36,40 & 37,14 & 36,90 & 36,42 & 35,94 & 35,38 & 37,94 \\
\hline $\mathrm{TiO}_{2}$ & 3,99 & 5,57 & 4,19 & 5,73 & 4,45 & 5,80 & 3,84 & 4,35 & 3,68 & 3,74 & 3,79 & 3,56 & 2,90 & 2,62 & 3,33 & 3,23 & 3,70 & 3,65 \\
\hline $\mathrm{Al}_{2} \mathrm{O}_{3}$ & 15,79 & 15,98 & 15,98 & 15,73 & 12,48 & 13,62 & 12,90 & 12,90 & 12,64 & 12,71 & 12,22 & 12,45 & 11,51 & 11,25 & 11,40 & 10,15 & 9,96 & 9,48 \\
\hline $\mathrm{Fe}_{2} \mathrm{O}_{3}$ & 0,63 & 0,95 & 0,71 & 0,70 & 1,70 & 1,10 & 2,50 & 2,58 & 2,90 & 3,13 & 2,98 & 3,04 & 4,16 & 4,50 & 4,06 & 5,06 & 5,90 & 5,03 \\
\hline $\mathrm{FeO}$ & 7,53 & 10,70 & 8,04 & 10,82 & 13,20 & 16,77 & 19,92 & 20,99 & 20,61 & 21,85 & 21,06 & 21,55 & 22,61 & 22,86 & 24,21 & 25,72 & 30,08 & 25,40 \\
\hline MnO & 0,06 & 0,08 & 0,09 & 0,06 & 0,06 & 0,15 & 0,38 & 0,37 & 0,44 & 0,38 & 0,32 & 0,42 & 0,32 & 0,43 & 0,49 & 0,43 & 0,42 & 0,33 \\
\hline $\mathrm{MgO}$ & 18,88 & 16,41 & 19,03 & 16,22 & 15,58 & 12,45 & 9,38 & 10,00 & 9,58 & 8,89 & 8,90 & 8,40 & 7,55 & 7,65 & 6,13 & 4,06 & 1,04 & 4,32 \\
\hline $\mathrm{BaO}$ & 0,99 & 1,66 & 0,63 & 1,38 & n.a. & n.a. & n.a & n.a & n.a & n.a & n.a & ก.a & n.a & n.a & n.a & n.a & n.a & n.a \\
\hline $\mathrm{CaO}$ & 0,05 & 0,09 & 0,02 & 0,03 & 0,01 & n.d. & n.d. & 0,03 & 0,03 & 0,10 & 0,01 & n.d. & n.d. & n.d. & 0,04 & 0,01 & 0,07 & 0,02 \\
\hline $\mathrm{Na}_{2} \mathrm{O}$ & 0,53 & 0,70 & 0,65 & 0,69 & 0,10 & 0,14 & n.d. & 0,01 & n.d. & n.d. & n.d. & n.d. & n.d. & n.d. & n.d. & n.d. & n.d. & n.d. \\
\hline $\mathrm{K}_{2} \mathrm{O}$ & 8,92 & 8,30 & 9,09 & 8,65 & 9,26 & 9,33 & 9,80 & 9,77 & 9,76 & 9,63 & 9,85 & 9,93 & 9,54 & 9,51 & 9,75 & 9,36 & 8,77 & 9,08 \\
\hline$F$ & 0,10 & 0,64 & 0,51 & 0,40 & 0,46 & 0,18 & 0,47 & 0,44 & 0,65 & 0,57 & 0,68 & 0,91 & 0,59 & 0,72 & 0,91 & 1,28 & 0,37 & 0,88 \\
\hline $\mathrm{Cl}$ & n.d. & 0,02 & n.d. & 0,01 & 0,11 & 0,06 & 0,12 & 0,15 & 0,09 & 0,16 & 0,24 & 0,26 & 0,25 & 0,30 & 0,15 & 0,26 & 0,45 & 0,23 \\
\hline $\mathrm{F}, \mathrm{Cl} \equiv \mathrm{O}$ & 0,04 & 0,27 & 0,21 & 0,17 & 0,21 & 0,09 & 0,23 & 0,22 & 0,29 & 0,28 & 0,34 & 0,44 & 0,31 & 0,37 & 0,41 & 0,60 & 0,26 & 0,42 \\
\hline Total & 96,02 & 96,23 & 96,30 & 96,18 & 96,60 & 96,75 & 95,80 & 97,16 & 96,27 & 97,21 & 96,52 & 96,48 & 96,26 & 96,37 & 99,77 & 94,90 & 95,88 & 95,94 \\
\hline $\mathrm{FeOt}$ & 8,10 & 11,55 & 8,68 & 11,44 & 14,73 & 17,76 & 22,17 & 23,31 & 23,22 & 24,67 & 23,74 & 24,29 & 26,35 & 26,91 & 27,86 & 30,27 & 35,39 & 29,93 \\
\hline$m g$ & 81,72 & 73,22 & 80,84 & 72,77 & 67,78 & 56,96 & 45,63 & 45,92 & 45,31 & 42,04 & 42,96 & 41,00 & 37,32 & 37,36 & 31,10 & 21,96 & 5,82 & 23,26 \\
\hline IAG & 0,67 & 0,63 & 0,68 & 0,67 & 0,82 & 0,76 & 0,82 & 0,82 & 0,84 & 0,82 & 0,87 & 0,86 & 0,90 & 0,92 & 0,93 & 1,00 & 0,95 & 1,04 \\
\hline
\end{tabular}




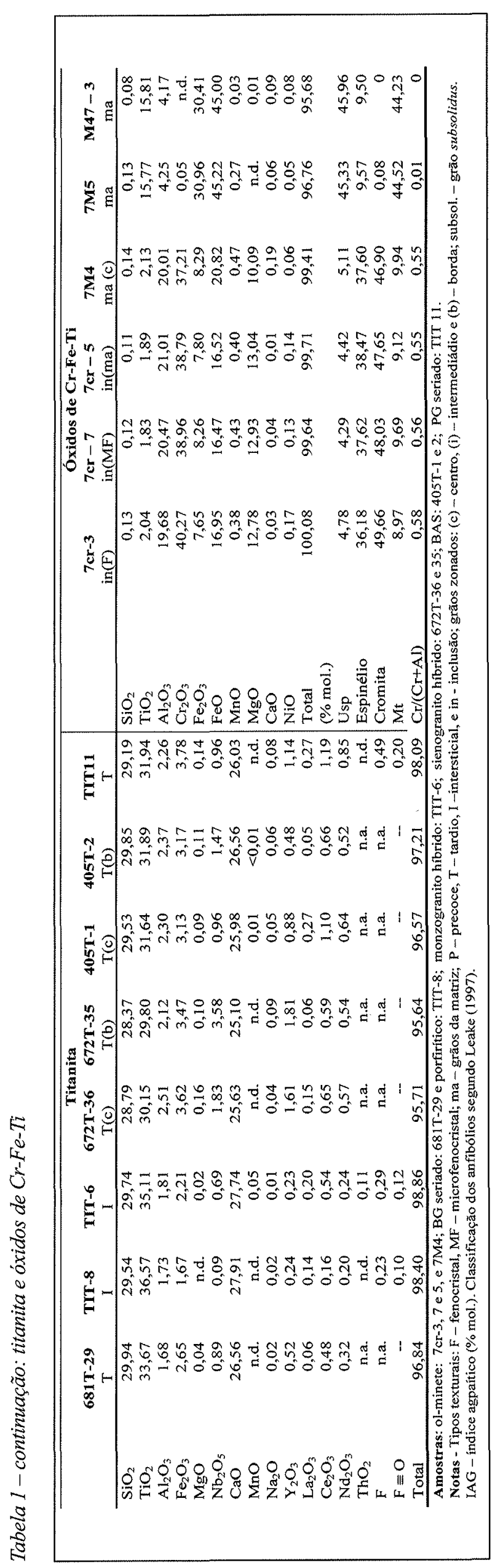

$0,65 \%$ ) e menor $\mathrm{NiO}$, indicando equilíbrio com magma mais diferenciado. A Mg-augita exibe grande variação na razão En: Fs, para pequeno declínio de Wo (Fig. 2A), característico de composições subalcalinas (Deer et al. 1978). Os valores de $m g$ nessa são de $85-80 \%$ em traquiandesito basáltico-TAB e espessartito, e mais variáveis entre traquiandesitos. Nas unidades efusivas 3 e 4 , o $m g$ da augita é similar ao das demais vulcânicas, e valores menores caracterizam as unidades 1 e 2 (77-70\%). O conteúdo de $\mathrm{Al}_{2} \mathrm{O}_{3}$ e $\mathrm{SiO}_{2}$ da $\mathrm{Mg}$-augita é inferior ao do Di do minete, e maior similaridade é observada com o do ol-minete (Figs. $2 \mathrm{~A}-\mathrm{C}$ ). As razões ${ }^{\mathrm{VI}} \mathrm{Al} /{ }^{\mathrm{IV}} \mathrm{Al}$ decrescem de espessartito, para TAB e traquiandesito, sugerindo equilíbrio sucessivamente a menor pressão, porém augita com ${ }^{\mathrm{V}} \mathrm{Al}$ extremamente baixo corresponde a grãos oxidados. A correlação da profundidade de cristalização entre a Mg-augita e o Di é dificultada face às diferenças composicionais que sugerem o equilíbrio com magma saturado em sílica e menos alcalino para a primeira. Mg-hastingsita do espessartito define trend em continuidade ao do anfibólio do minete/vogesito, com menor FeO* e maior $\mathrm{SiO}_{2} / \mathrm{Al}_{2} \mathrm{O}_{3}$ (Fig. 2E). O conteúdo de $\mathrm{TiO}_{2}$ é similar ao da $\mathrm{Fe}$-pargasita do minete, porém permanece inalterado ou decresce suavemente com o decréscimo de $\mathrm{FeO}^{*}$, e de ${ }^{\mathrm{V}} \mathrm{Al}+$ IVAl (Fig. 3B). Tais variações parecem traduzir diferenciação paralela à descompressão, o que é compatível com o desenvolvimento de coroas de magnetita ao redor da $\mathrm{Mg}$-hastingsita, típico destas rochas (Lima \& Nardi 1991).

MONZODIORITO ARROIO DO JACQUES E MONZONITOS Maior conteúdo de $\mathrm{FeO}_{1}$ e baixo $\mathrm{Fe}_{2} \mathrm{O}_{3}$ na Mg-augita e Fe-enstatita do MAJ, ambos sugerem cristalização em condições de moderada a baixa $f \mathrm{O}_{2}(\sim$ oxy-buffer $\mathrm{QFM})$, consistente com o predomínio de ilmenita entre as fases óxido e de pigeonita invertida (Grove \& Juster 1989, Toplis \& Carroll 1995). A Fe-enstatita $\left(\mathrm{Fs}_{33-37}\right)$ possui $m g(66-63 \%)$ comparável ao da $\mathrm{Ol}$ de traquiandesitos-TAB (Fig. 2A, Tab. 1). A Mg-augita é mais cálcica que a dessas vulcânicas (Fig. $2 \mathrm{~A}$ ) e tem ${ }^{\mathrm{VI}} \mathrm{Al} /{ }^{\mathrm{V}} \mathrm{Al}$ igual ou superior (Fig. 2B), porém exibe conteúdo similar de $\mathrm{FeO}_{t}, \mathrm{MgO}$ e $\mathrm{TiO}_{2}$, com $m g$ de 74-71\%. $\mathrm{Al}_{2} \mathrm{O}_{3}$ e $\mathrm{SiO}_{2}$ são equiparáveis aos da augita do TAB, porém os valores altos e extremos de $\mathrm{SiO}_{2}$ correspondem a grãos alterados e exsolvidos (Fig. 2C). A Mg-hornblenda, em uma amostra do MAJ, exibe $m g$ similar ao da augita $(\sim 73 \%)$, e baixo $\mathrm{TiO}_{2}$ e $\mathrm{Al}_{2} \mathrm{O}_{3}$ (Tab. 1), indicativo do equilíbrio a baixa temperatura e pressão. A Mg-biotita possui $m g$ de $68-57 \%$, $\mathrm{TiO}_{2}$ moderado a alto $(4,0-5,8 \%)$ e exibe correlação negativa $\mathrm{Mg}-\mathrm{Al}$ (Fig. 4A).

Nos monzonitos, anfibólio e biotita mostram maiores analogias com os do MAJ, e os contrastes ocorrem no piroxênio (Figs. 2A-C). A augita/diopsídio exibe baixo $\mathrm{Al}_{2} \mathrm{O}_{3}$ e $\mathrm{SiO}_{2}$, de modo que é deficiente em ${ }^{\mathrm{V}} \mathrm{Al}$, típico do equilíbrio em níveis crustais rasos. A Mg-hornblenda possui baixo $\mathrm{TiO}_{2}$ e alto ${ }^{\mathrm{M}} \mathrm{Ca}$, porém é menos evoluída, com menor $\mathrm{Si}$ (Fig. $3 \mathrm{~A}$ ) e $\mathrm{Al}$ igual ou superior (Fig. 3B), sugerindo cristalização a maior pressão e temperatura que o anfibólio do MAJ. Contudo, a forte zonação do anfibólio, em uma amostra do MT, registra ambiente submetido a abrupto decréscimo na pressão (4-5 para $2 \mathrm{kbar}$ ), como sugere o declínio de $\mathrm{Al}_{\text {t }}$ (Fig. 3B). A Mg-biotita exibe menor $\mathrm{Mg}$ indicando cristalização a partir de líquido mais evoluído (Fig. 4A).

GRANITOS Fe-hornblenda e Fe-biotita são os máficos dominantes nos granitos. No pertita granito (PG) equigranular, a $\mathrm{Fe}$-hornblenda transiciona para $\mathrm{Fe}$-barroisita e a Fe-biotita para anita (Tab. 1). Em todos, a mica é deficiente ou contém baixo ${ }^{\mathrm{IV}} \mathrm{Al}$, e exibe $\mathrm{TiO}_{2}$ moderado a alto (2-5\%). A evolução na composição de anfibólio e biotita dos granitos é concordante, caracterizada por variações no conteúdo de $\mathrm{FeO}_{\mathrm{t}}, \mathrm{MgO}$ e $\mathrm{Al}_{2} \mathrm{O}_{3}$ traduzindo o crescimento de alcalinidade e razão $\mathrm{FeO}^{*}$ (Figs. 


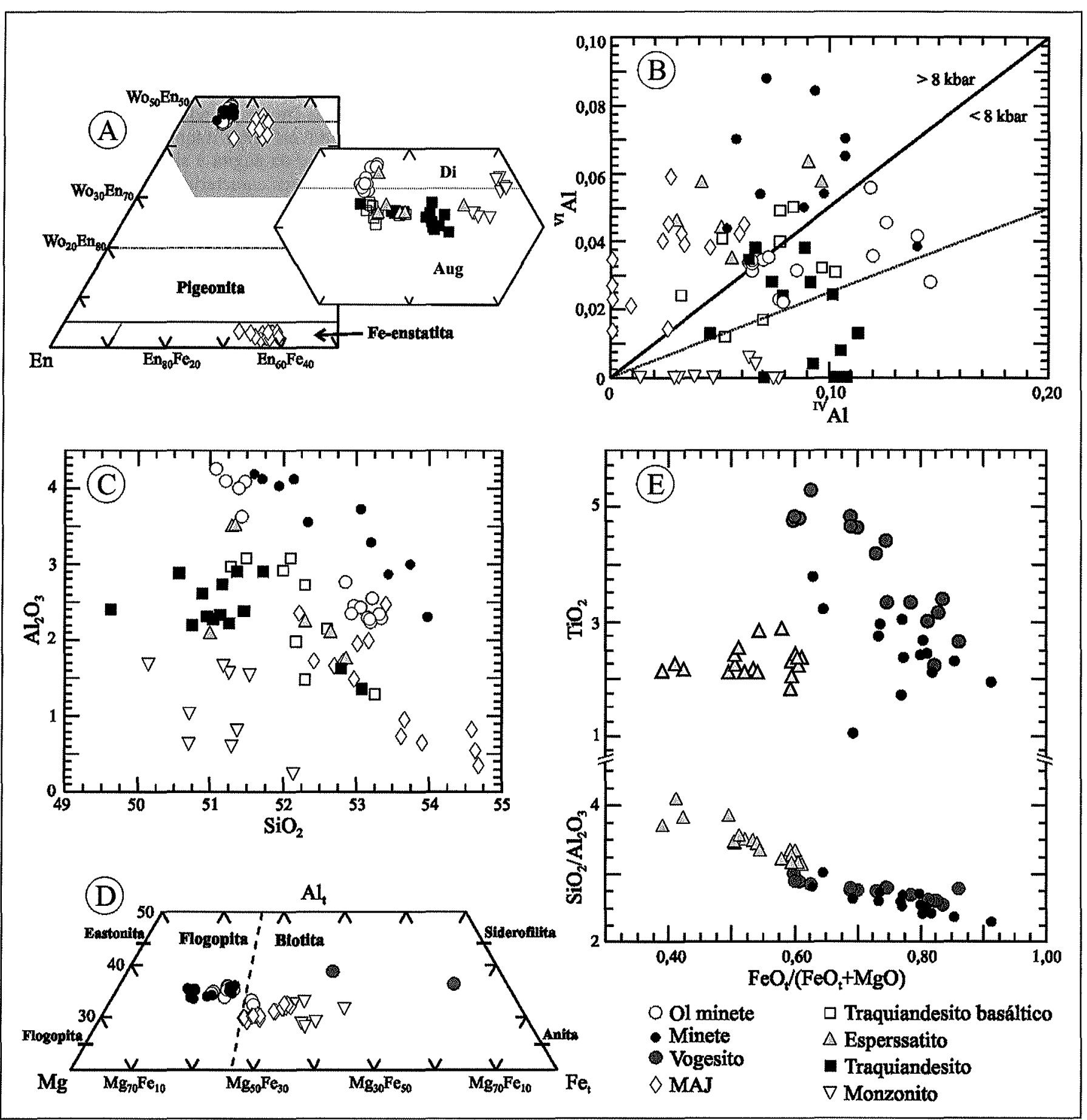

Figura 2 - Composição de piroxênios (A-C), micas ferromagnesianas (D) e anfibólios (E) de minetes, vogesito e monzodiorito Arroio do Jacques (MAJ), comparadas a de rochas intermediárias da Formação Hilário (Lima 1995). A-Seção do diagrama quadrilateral Wo-En-Fs, com os campos de classificação de clinopiroxênio (Di-diopsídio, e Aug - augita) e ortopiroxênio (Morimoto

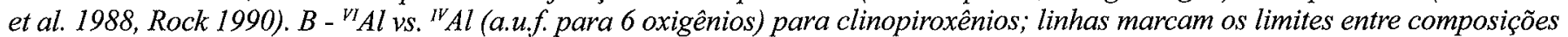
de rochas máficas alcalinas equilibradas em condições de alta e baixa pressão: pontilhada segundo Wass (1979), e grossa segundo Perugini et al. (2003). $\mathrm{C}-\mathrm{Al}_{2} \mathrm{O}_{3}$ vs. $\mathrm{SiO}$ (\% peso) para clinopiroxênios. $\mathrm{D}$-Seção do diagrama Al-Mg-Fe, (a.u.f. para 22 oxigênios), exibindo a composição de membros extremos de micas ferromagnesianas. $\mathrm{E}-\mathrm{TiO}_{2}$ e $\mathrm{SiO}_{2} / \mathrm{Al}_{2} \mathrm{O}_{3}$ vs. $\mathrm{FeO} /(\mathrm{FeO}+\mathrm{MgO})(\%$ peso) para anfibólios.

3A-4). Magnetita quase pura indica a maior intensidade de reequilíbrio subsolidus nos tipos do núcleo, enquanto nos alcalinos, Ti-magnetita e ilmenita exibem conteúdo mais elevado e variado de $\mathrm{TiO}_{2}$ (Gastal et al. 2006b). A titanita, exceto no monzogranito, exibe razão $\mathrm{Fe}: \mathrm{Al}$ próximo a 1:1 (Fig. 5A), típica de rochas ígneas (Kowallis et al. 1997).
Granitos do núcleo No granodiorito (BG) e monzogranito híbrido (ABM), anfibólio e biotita exibem composições homogêneas. $\mathrm{O}$ anfibólio destes, junto ao de monzonitos e MAJ, define trend marcado pelo crescimento de Si para valores quase constantes de ${ }^{\mathrm{M}} \mathrm{Ca}$ (trend actinolítico - Fig. 3A), típico de magmas residuais não-alcalinos (Mitchell 1990). Igualmente, a composição da biotita segue o trend intrafácies ("b" - Fig. 4B, Stussi 


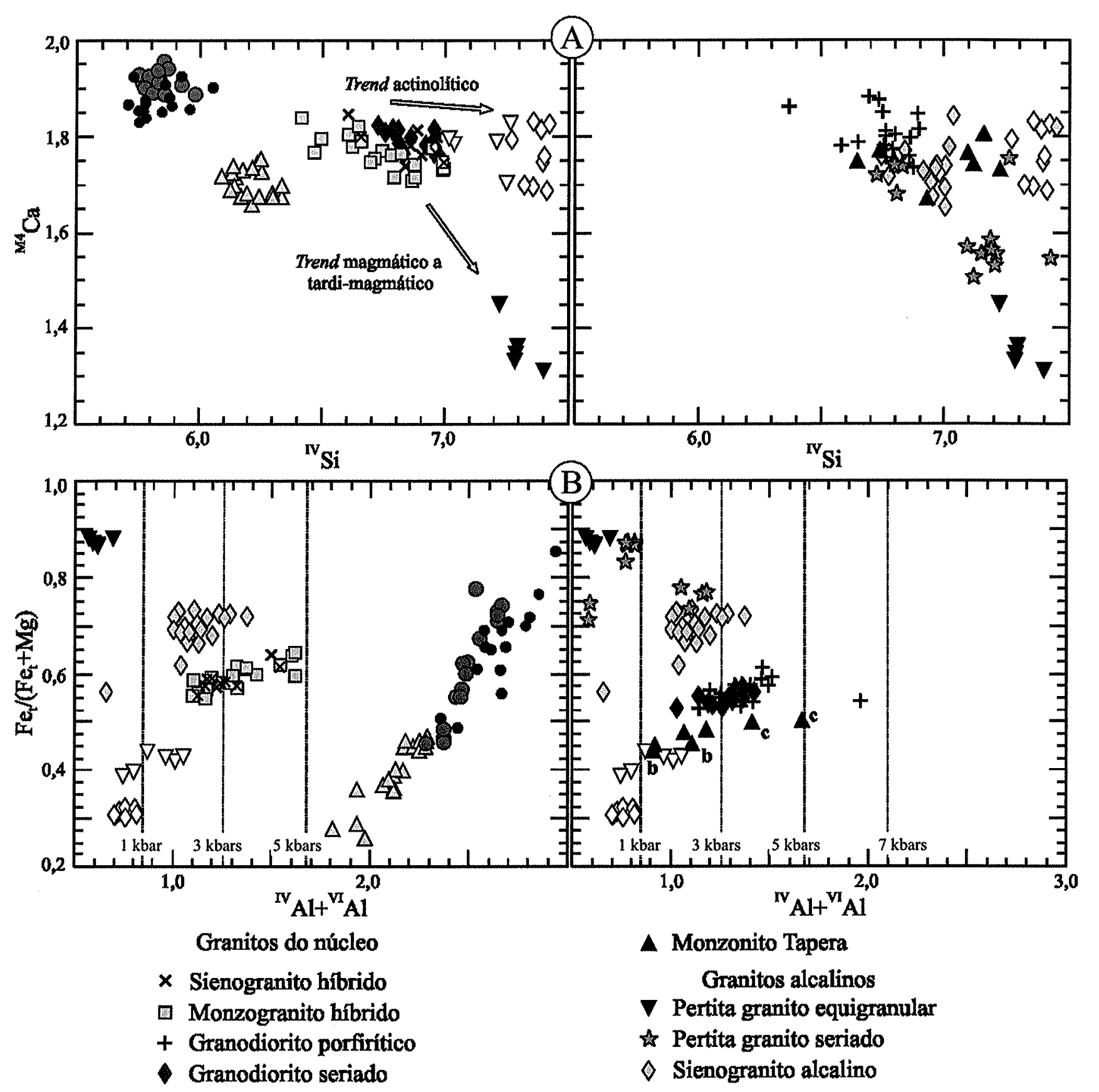

Figura 3 - Diagramas exibindo a composição de anfibólio de granitóides do CILS (excluindo análises de grãos alterados), comparado ao de minetes, vogesito e espessartito. Os dois diagramas são repetidos para evitar a superposição de pontos. $A-{ }^{M 4} C a$

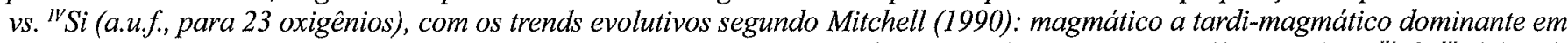
associações alcalinas, e actinolítico (subsolidus) típico de líquidos residuais não alcalinos. $B-F e /(F e+M g) v s .{ }^{l V} A l+{ }^{V I} A l(a . u . f$, para 23 oxigênios), exibindo as isóbaras segundo calibração de Schmidt (1992, in Anderson \& Smith 1995); c-centro e b-borda do grão. Demais símbolos como na figura 2.

\& Cuney 1996), fortalecendo o vínculo genético desses granitóides. $\mathrm{O}$ decréscimo regular de $\mathrm{TiO}_{2}$ e $\mathrm{Al}_{2} \mathrm{O}_{3}$, e o crescimento de $\mathrm{FeO}^{*}$ e $\mathrm{SiO}_{2}$ marcam a evolução da biotita nos tipos do núcleo. $\mathrm{O}$ anfibólio, contudo, traduz particularidades decorrentes das condições de oxi-redução e do lento soerguimento durante a cristalização, de acordo com o indicativo de pressão com base no $\mathrm{Al}_{\mathrm{t}}$ (Fig. 3B, Anderson \& Smith 1995). Nos tipos híbridos, o decréscimo na pressão registrado pelo anfibólio (4,5-4,0 para 2,0-3,0 kbar) acompanha a evolução, porém o inverso parece ocorrer entre os tipos de BG. No BG porfirítico e mais diferen- ciado, a mudança na composição do anfibólio sugere a recarga com novo pulso de magma. Variações na $\mathrm{fO}_{2}$ são evidenciadas pela divergência entre as razões $\mathrm{FeO}^{*}$ de fases máficas (biotita e anfibólio) e da rocha-RT (Gastal et al. 2006b). FeO ${ }_{\text {ANF-BTA }}^{*}$ permanece constante ou decresce com o aumento de FeO* indicando ambiente oxidante que é mais pronunciado no BG. Nos sienogranitos híbridos, particularidades na composição da biotita e titanita sugerem algum tipo de interação com magma alcalino. No BG, a titanita se aproxima da composição ideal, exibindo menor $\mathrm{Fe}$ e $\mathrm{Al}$ e baixas concentrações de ETRL (ele- 


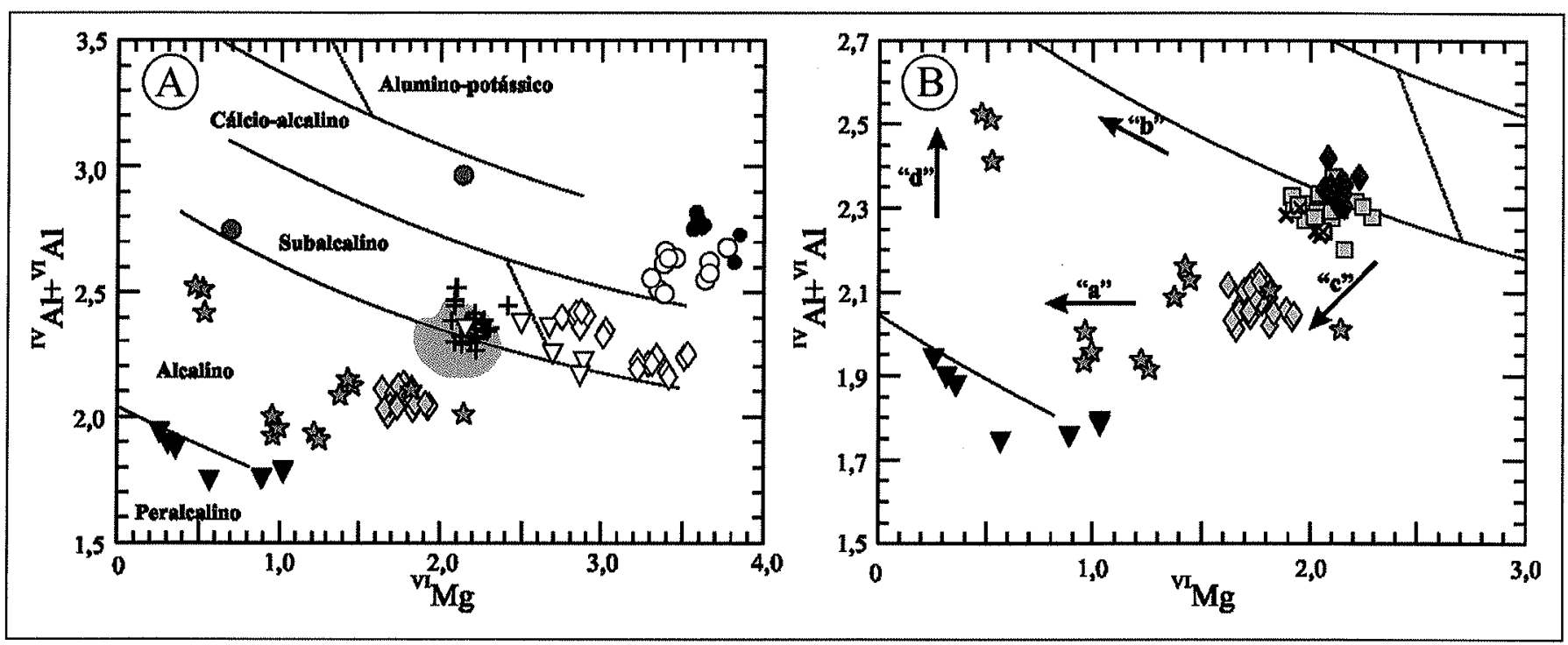

Figura 4 - Diagrama Al, vs. Mg (a.u.f., para 22 oxigênios) exibindo a composição de biotita de granitos do CILS, comparados a das demais rochas ígneas consideradas (excluindo lamelas alteradas). Separação dos granitos segundo Nachit et al. (1985); campo cinza em (A) para biotita de granodiorito seriado e granitos hibridos do CILS, discriminados em (B); setas realçam trends evolutivos segundo Stussi \& Cuney (1996): " $a$, b e d" dominantes na diferenciação intrafácies, $e$ "c" marca as variações interfácies devido ao aumento da alcalinidade. Símbolos como nas figuras 2 e 3.

mentos terras raras leves), $\mathrm{Y}$ e $\mathrm{Nb}$ (Fig. 5). No ABM a titanita é similar, porém o conteúdo de Al é mais elevado e variado, enquanto no sienogranito híbrido, esta é análoga a de granitos alcalinos, com $\mathrm{Fe}$, $\mathrm{Y}$ e $\mathrm{Nb}$ elevados.

Granitos alcalinos No sienogranito (BAS) e pertita granito (PG), a evolução do anfibólio, evidenciada por forte decréscimo de $\mathrm{MgO}$ e $\mathrm{Al}_{2} \mathrm{O}_{3}$ (Tab. 1), é também marcada por decréscimo de ${ }^{\mathrm{M} 4} \mathrm{Ca}$ paralelo ao trend magmático a tardi-magmático de associações alcalinas (Fig. 3A, Mitchell 1990). Os contrastes na biotita são abruptos e seguem o trend típico da evolução interfácies ("c"- Fig. 4B, Stussi \& Cuney 1996), resultante da alcalinidade crescente, com alguma dispersão talvez devido ao efeito diversificado da fase volátil tardi a pós-magmática (Fig. 4). As razões $\mathrm{FeO}^{*}$ de biotita, anfibólio e rocha tendem a convergir com a diferenciação destes granitos (Gastal et al. 2006b), de modo que registram cristalização em ambiente com $\mathrm{fO}_{2}$ controlada pelo equilíbrio mineral. Nestas condições, o decréscimo na proporção de biotita compensado pela Ti-magnetita, no PG dominante, implica em pressão decrescente durante a cristalização. $O$ forte declínio de $\mathrm{Al}$ no anfibólio destes granitos não pode ser atribuído ao decréscimo de pressão (Fig. 3B), porque o geobarômetro não se aplica a composições com elevado $\mathrm{Fe} /(\mathrm{Fe}+\mathrm{Mg})$ e baixo $\mathrm{Al}_{\mathrm{t}}$ (Anderson \& Smith 1995). Porém, pressões da ordem de 2-3 kbar são sugeridas para a cristalização do BAS $\left(\mathrm{Fe} /\left(\mathrm{Fe}_{\mathrm{t}}+\mathrm{Mg}\right)\right.$ $\sim 0,6$ ). A titanita é rica em Fe, ETR, Nb e Y (Figs. 5), traduzindo a natureza da fase fluida típica de granitos alcalinos (Wang et al. 2001). O forte papel da diferenciação na composição de fases máficas sugere líquidos residuais levemente peralcalinos. Assim, o granito Estrela pode representar o extremo fracionamento de magma similar ao dos tipos alcalinos do CILS. Isto é indicado pela evolução de Fe-barroisita (PG) para arfvedsonita do GE, que segue a mesma tendência com forte decréscimo de $\mathrm{Al}, \mathrm{Mg}$ e Ca e crescimento de $\mathrm{Fe}_{\mathrm{t}}, \mathrm{Fe}^{+3}$ e $\mathrm{Na}$ (Tab. 1).

Litogeoquímica Elementos maiores e alguns traços de amostras representativas de minetes, MAJ, granitos do CILS e GE estão na tabela 2. São também incluídas amostras de traquiandesitos, espessartito e monzonitos da Formação Hilário (Lima 1995).
ROCHAS INTERMEDIARIAS A BÁSICAS Lamprófiros, traquiandesitos e MAJ são metaluminosos (IAG < 0,9, Tab. 2) e, com exceção dos minetes, plotam no campo alcalino saturado em sílica no diagrama álcalis-sílica (Fig. 6A). Os dois minetes são ol-ne normativos e exibem alta razão Nb/Y (Fig. 6B). Possuem $\mathrm{K}_{2} \mathrm{O}$ superior a $3 \%$ e $\mathrm{K}_{2} \mathrm{O} / \mathrm{Na}_{2} \mathrm{O}(\%$ mol.) próximo a 1 (veja Fig. 8B), porém são potássicos e não ultrapotássicos, conforme Foley et al. (1987), devido a razão $\mathrm{K}_{2} \mathrm{O} / \mathrm{Na}_{2} \mathrm{O}$ (\% mol) $<2$. As demais rochas são ol-hy ou $q$-hy normativas, e exibem menor $\mathrm{Nb} / \mathrm{Y}$, o que as aproxima de composições subalcalinas (Fig. 6B). Possuem $\left(\mathrm{Na}_{2} \mathrm{O}-1\right)<\mathrm{K}_{2} \mathrm{O}$, sendo comumente relacionadas à série shoshonítica (Lima \& Nardi 1998). Segundo critérios de Muller \& Groves (1997), as rochas básicas a intermediárias associadas ao CILS são tipos potássicos pós-colisionais, ou de arcos continentais (Fig. 7). Os minetes, com elevado $\mathrm{Zr}$ e Y (Fig. 7A) e $\mathrm{TiO}_{2} / \mathrm{Al}_{2} \mathrm{O}_{3}$ (Fig. 7B), representam a transição para composições alcalinas comum em ambientes pós-colisionais. Os traquiandesitos, entretanto, com razões $\mathrm{Zr} / \mathrm{TiO}_{2}$ elevadas ( $z$ 200, Fig. 7B) e alto conteúdo de Sr (Tab. 2, veja Fig. 9), são consistentes com arcos continentais.

Minetes Os dois tipos exibem elevada perda ao fogo(PF - Tab. 2), permitindo suspeitar de eventos hidrotermais superpostos. Contudo, a mineralogia exibe alteração seletiva. Enquanto a $\mathrm{Ol}$ é substituída por serpentina e carbonato, o Di, a flogopita e o feldspato mostram-se inalterados. As duas rochas retêm altas concentrações de elementos litófilos ( $\mathrm{K}, \mathrm{Ba}, \mathrm{Rb}$ e $\mathrm{Sr}$ ), inconsistente com a intensa mobilidade ocasionada por fluidos hidrotermais. No ol-minete, a Ol mais magnesiana (647-o2, Tab. 1) exibe coeficiente de partição Fe-Mg $\left(\mathrm{Kd}_{\mathrm{Fc}-\mathrm{Mg}}\right.$ ol-RT) de 0,30 , compatível com o equilíbrio Ol-magma (Roeder \& Emslie 1970). A composição desta é similar a da Ol liquidus obtida pelo programa Melts (Ghiorso \& Sack 1995, Asimov \& Ghiorso 1998), para a amostra $647 \mathrm{~A}-1$. Os valores de $\log f \mathrm{O}_{2}$ (expresso como $\triangle \mathrm{NNO}=$ $\log f \mathrm{O}_{2}^{\mathrm{RT}}-\log f \mathrm{O}_{2}{ }^{\mathrm{NNO}}$, Fig. 8A), calculados para os dois minetes (Tab. 2), são consistentes com os obtidos para o fracionamento da mesma amostra a $1 \mathrm{kbar}$ e $2,3 \% \mathrm{H}_{2} \mathrm{O}(\Delta \mathrm{NNO}=0,62$ a 0 entre $1294^{\circ}-1100^{\circ} \mathrm{C}$ ). Estes resultados sugerem pequena modificação pós-cristalização, permitindo assumir que as variações químicas 

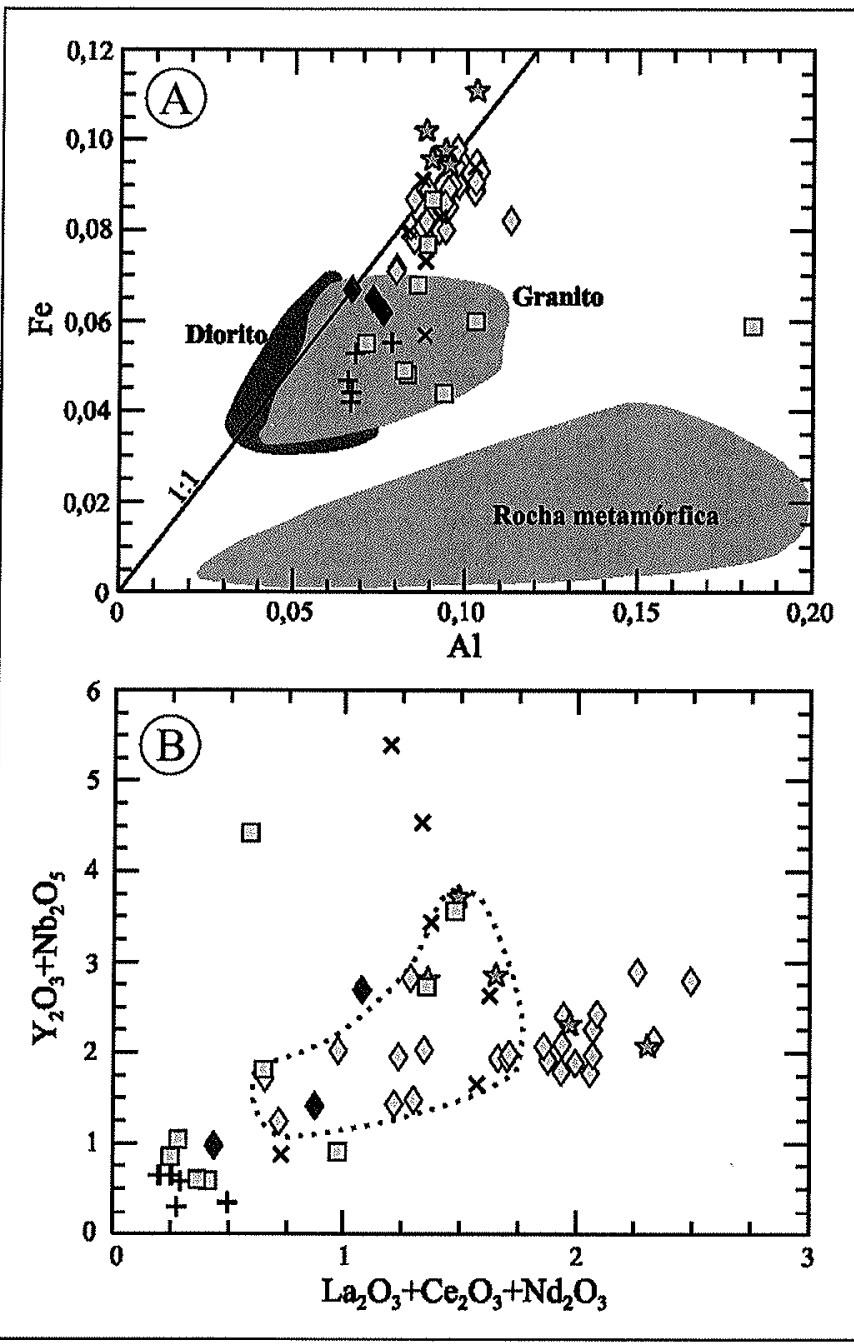

Figura 5 - Diagramas exibindo a composição de titanita de granitos do CILS. A - Fe vs. Al (a.u.f. para 3 cátions), com os campos de rochas metamórficas e igneas segundo Kowallis et al. (1997); $\mathrm{B}-\left(\mathrm{Y}_{2} \mathrm{O}_{3}+\mathrm{Nb}_{2} \mathrm{O}_{5}\right)$ vs. $\left(\mathrm{La}_{2} \mathrm{O}_{3}+\mathrm{Ce}_{2} \mathrm{O}_{3}+\mathrm{Nd}_{2} \mathrm{O}_{3}\right)(\%$ peso), salientando as diferenças entre os granitos do CILS. Linha pontilhada marca a titanita de granitos alcalinos referentes à borda de grãos ou grãos subsolidus, intersticiais ou sobrepostos ao anfibólio, e de tonalidades mais claras. Símbolos como na figura 3.

entre os dois minetes refletem processos ígneos. Pequeno desvio na química original pode ainda ser devido à remoção parcial de materiais estranhos (vogesito e microxenólitos).

Ol-minete e minete exibem valores primitivos de $m g$ (75$67 \%$, Tab. 2 e Fig. 8 ), porém o primeiro é o que melhor se enquadra como magma primitivo, com $\mathrm{FeO}_{\mathrm{t}} / \mathrm{MgO}<1$ e moderado $\mathrm{Cr}$. A presença de $\mathrm{Mg}$-cromita aluminosa (Tab 1), e o $\mathrm{Kd}_{\mathrm{Fe}-\mathrm{Mg}}(\mathrm{Ol}$ RT) reforçam tal conclusão. Esta rocha não satisfaz os critérios petrográficos de um lamprófiro (Rock 1991), uma vez que os fenocristais de flogopita são escassos. O elevado $\mathrm{TiO}_{2}(>1,3 \%)$, a baixa razão molar $\mathrm{Al}_{2} \mathrm{O}_{3} / \mathrm{TiO}_{2}(<5)$ e a presença de Ti-flogopita rica em $\mathrm{Ba}$, similar a do minete (Tab. 1), distinguem-na dos absarokitos (Foley et al. 1987, Muller \& Groves 1997), e permitem classificá-la como ol-minete à semelhança do efetuado por Carmichael et al. (1996). Os dois tipos exibem conteúdo similar de $\mathrm{TiO}_{2}, \mathrm{CaO}, \mathrm{Na}_{2} \mathrm{O}$ e $\mathrm{Rb}$, porém o minete contém menor $\mathrm{MgO}$, $\mathrm{SiO}_{2}, \mathrm{Cr}$ e Ni, e maior $\mathrm{Al}_{2} \mathrm{O}_{3}, \mathrm{FeO}_{t}, \mathrm{~K}, \mathrm{O}, \mathrm{P}_{2} \mathrm{O}_{5}, \mathrm{Nb}, \mathrm{Zr}, \mathrm{Y}, \mathrm{Ba}, \mathrm{Sr}$ e ETR (Tab. 2, Figs. 8 e 9). A evolução entre eles, portanto, é marcada por aumento da subsaturação em sílica com o decrés- cimo de $m g$, dificil de ser explicado pelo simples fracionamento mineral, como ilustra a figura $9 \mathrm{C}$. $\mathrm{O}$ forte enriquecimento em elementos incompatíveis (ETRL, $\mathrm{Ba}, \mathrm{Th}, \mathrm{P} \mathrm{e} \mathrm{Y}$ ) e o padrão mais fracionado de ETR $\left(\mathrm{Ce} / \mathrm{Yb}_{\mathrm{N}} \sim 50\right.$, Fig. 10A-B), no minete, pode ser decorrente de menor grau de fusão parcial ou maior enriquecimento da fonte mantélica. Contudo, a natureza química particular desta rocha pode ter resultado da mistura minete-vogesito, como evidencia a mineralogia. Ambos exibem anomalia negativa de $\mathrm{Nb}\left(\mathrm{La} / \mathrm{Nb}_{\mathrm{N}}\right.$ de 2-3), sugerindo fonte mantélica vinculada de alguma forma com a subduç̧ão.

Rochas saturadas a supersaturadas em silica Os traquiandesitos basálticos-TAB, com $m g$ de 75-70\%, possuem composições primitivas $(\mathrm{FeO} / \mathrm{MgO}<1$ e moderado $\mathrm{Cr}$ e Ni). Escolheu-se a amostra Bas-09 (Lima 1995), para representar o outro magma parental de derivação mantélica com maior sílica e baixa razão $\mathrm{K}_{2} \mathrm{O} / \mathrm{Na}_{2} \mathrm{O}(\sim 0,35$, Fig. $8 \mathrm{~B})$. As amostras com $m g$ superior a $75 \%$, e elevado $\mathrm{Cr}$ e $\mathrm{Ni}$, são interpretadas como cumulados de Ol e talvez clinopiroxênio (Lima 1995, Figs. 8 e 9). Os valores do $\mathrm{Kd}_{\mathrm{Fe}-\mathrm{Mg}}$ (Ol-RT) são elevados $(\sim 1,0-1,5)$, e os de $\triangle \mathrm{NNO}$ estão, em média, uma unidade acima dos calculados pelo Melts para o fracionamento da amostra Bas-09, a 1 kbar e saturação em $\mathrm{H}_{2} \mathrm{O}\left(\mathrm{NNO}+0,24 \mathrm{a}+0,34\right.$, entre $\left.1270^{\circ}-1070^{\circ} \mathrm{C}\right)$. Isto indica re-equilíbrio da $\mathrm{Ol}$ com líquido residual e oxidação pós-erupção. Comparado ao ol-minete, o TAB possui menor $\mathrm{K}_{2} \mathrm{O}, \mathrm{CaO} /$ $\mathrm{Al}_{2} \mathrm{O}_{3}, \mathrm{FeO}_{1}, \mathrm{TiO}_{2}, \mathrm{Rb}, \mathrm{Ba}$, Sr e $\mathrm{Zr}$ e maior $\mathrm{Na}_{2} \mathrm{O}$ e $\mathrm{SiO}_{2}$ (Tab. 2, Figs. 8 e 9). Diferenças estas impossíveis de serem resolvidas pelo fracionamento do magma ol-minete, implicando em gênese diversa. $\mathrm{O}$ decréscimo de $\mathrm{SiO}_{2}$ (Fig. $8 \mathrm{C}$ ), e o crescimento de FeO (Fig. 8E) e $\mathrm{Zr}$ (Figs. 9D e G), em algumas amostras de $\mathrm{TAB}$, sugerem contaminação com líquido derivado do ol-minete. Contudo, anomalias negativas pronunciadas de $\mathrm{Nb}-\mathrm{Ti}-\mathrm{P} \mathrm{e}$ padrão menos fracionado de ETR (Fig. 10D), com quebra pronunciada de ETRM (ETR médios), requerem contribuição de fonte distinta para o TAB.

As demais rochas, em geral, acompanham o trend de fracionamento do magma $\mathrm{TAB}$, controlado por $\mathrm{Ol}+\mathrm{Cpx}$ (Figs. 8C-F, $9 \mathrm{~B}-\mathrm{C}$ e F-G). Diferem entre si quanto às razões $\mathrm{K}_{2} \mathrm{O} / \mathrm{Na}_{2} \mathrm{O}$ (Fig. 8B). Espessartitos e MAJ exibem razões intermediárias entre TAB-traquiandesitos $(<0,5)$ e os minetes $(\sim 1)$. Comparados aos traquiandesitos, os primeiros contêm álcalis e $\mathrm{SiO}_{2}$ igual ou superior, mas tendem a ser mais magnesianos (Tab. 2, Figs. 6A e 8), e exibem forte crescimento de $\mathrm{Rb}$ com o decréscimo de $m g$ (Figs. 9A e E). O MAJ, contudo, é pobre em Y (Fig. 7A) e contém maior $\mathrm{TiO}_{2}$ (Fig. 8F). As razões $\mathrm{TiO}_{2} / \mathrm{Al}_{2} \mathrm{O}_{3}$ (Fig. 7B), e os padrões de elementos incompatíveis e de ETR (Figs. 10A-B) deste sugerem a proximidade com o ol-minete. O MAJ difere pelas anomalias negativas mais pronunciadas de $\mathrm{Nb}$ e $\mathrm{Th}$, o que poderia ser um indicativo de contribuição infracrustal. Valores de $f \mathrm{O}_{2}$, de NNO-1, são concordantes com os calculados para o fracionamento da amostra K1 89, pelo Melts para 3-4 kbar e condições anidras, envolvendo dois Cpx e Pl. As amostras de MAJ alteradas ou com anfibólio tardi-magmático estão mais oxidadas $(\Delta \mathrm{NNO}>-1)$, justificando a separação efetuada. Essas mostram forte crescimento de $\mathrm{SiO}_{2}$ para conteúdo equivalente de álcalis (Fig. $6 \mathrm{~A}$ ), consistente com a interação do MAJ com líquidos monzoníticos como sugerem as relações de campo e petrografia.

Variações químicas mais regulares caracterizam as amostras de espessartito com $\triangle N N O \leq 2$ (Figs. 8 e 9). Processos pós-cristalização parecem ter prevalecido em amostras mais oxidadas $(\triangle N N O>2)$ de espessartito e traquiandesitos (unidades 2 e 3 ), uma vez que o $\triangle \mathrm{NNO}$ mostra correlação positiva com $m g$ e PF. Nesses traquiandesitos, a maior dispersão de $\mathrm{Rb}$ e $\mathrm{Sr}$ corrobora tal conclusão, e resulta no decréscimo de $\mathrm{Rb} / \mathrm{Sr}$ com a diferenciação. $\mathrm{Sr}, \mathrm{Zr}$ e Ba são mais elevados nas efusivas 3 (Figs. 9B-D), e algum tipo de interação com o minete é sugerida pela 
Tabela 2 - Elementos maiores e alguns traços para amostras representativas de minetes, granitóides do CILS, vulcânicas correlatas e granito Estrela.

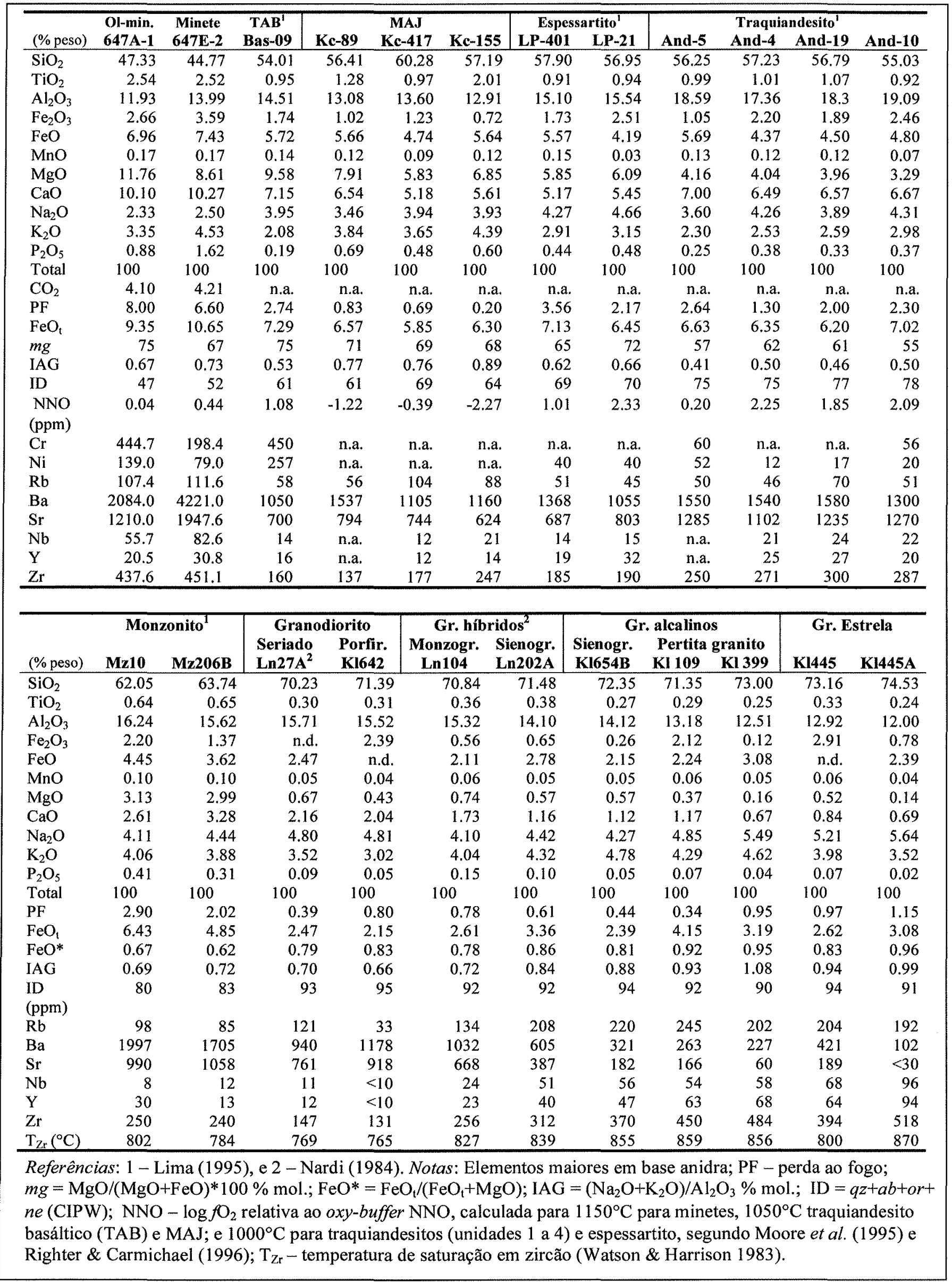




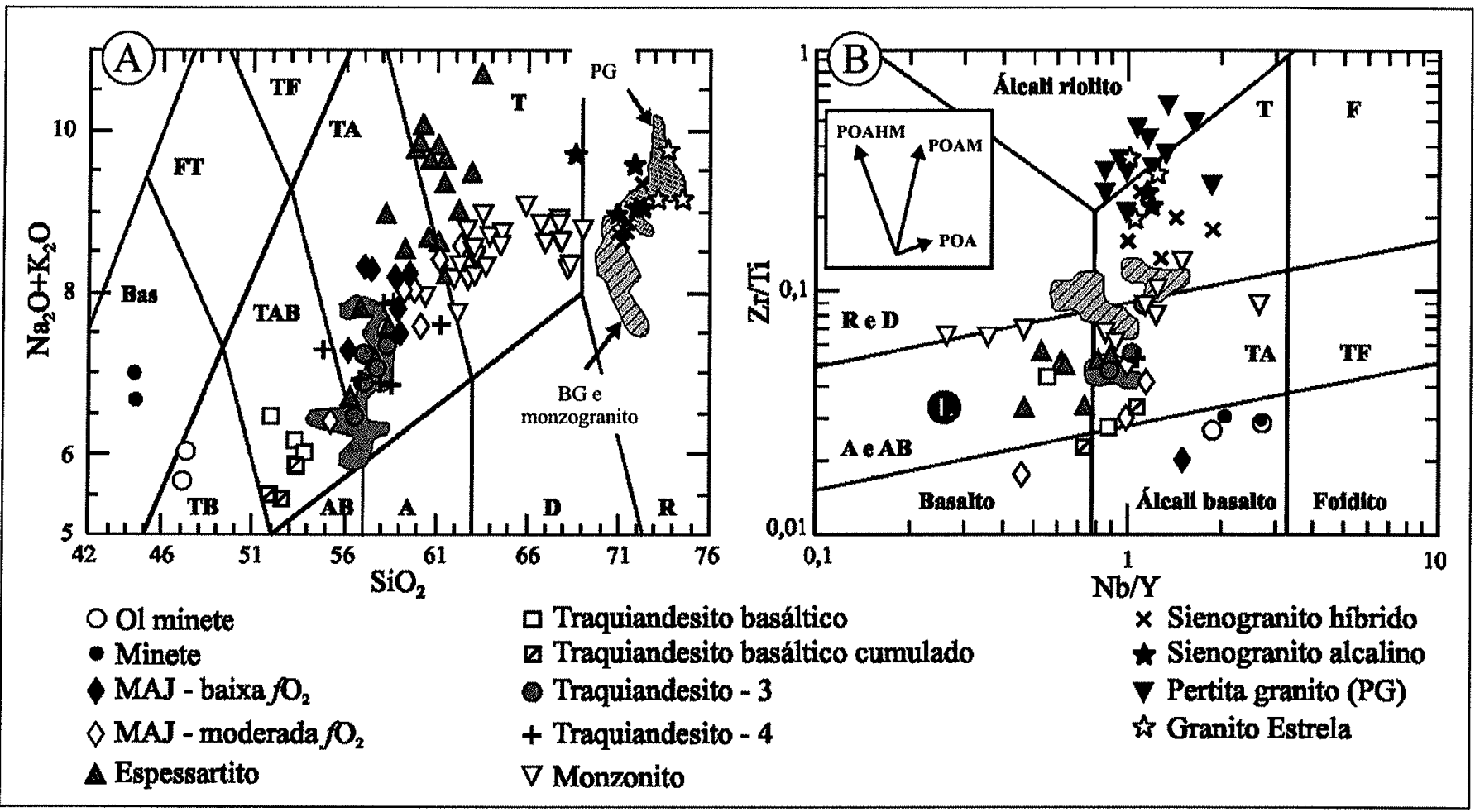

Figura 6-Diagramas classificatórios para as rochas do CILS e vulcânicas correlatas. A-Álcalis vs. SiO, (base anidra), com os campos segundo Le Maitre et al. (1989). B-Zr/Ti vs. Nb/Y com os campos de Winchester \& Floyd (1977) modificados por Pearce (1996a). $L$-crosta inferior e vetores de fracionamento mineral para: POA - Pl+Ol+Aug, POAM - inclui magnetita e POAHM - inclui hornblenda. Campos: TF-tefrifonolito, FT-fonotefrito, Bas - basanito/tefrito, TA-traquiandesito, TAB - traquiandesito basáltico, TB - traquibasalto, $T$-traquito, $A B$ - andesito basáltico, $A$-andesito, $D$ - dacito e $R$ - riolito. Tipos de $M A J$ quanto à $\mathrm{fO}_{2}$ como na figura $9 \mathrm{~A}$; cinza para unidades 1 e 2 dos traquiandesitos, e hachurado como indicado em $A$.
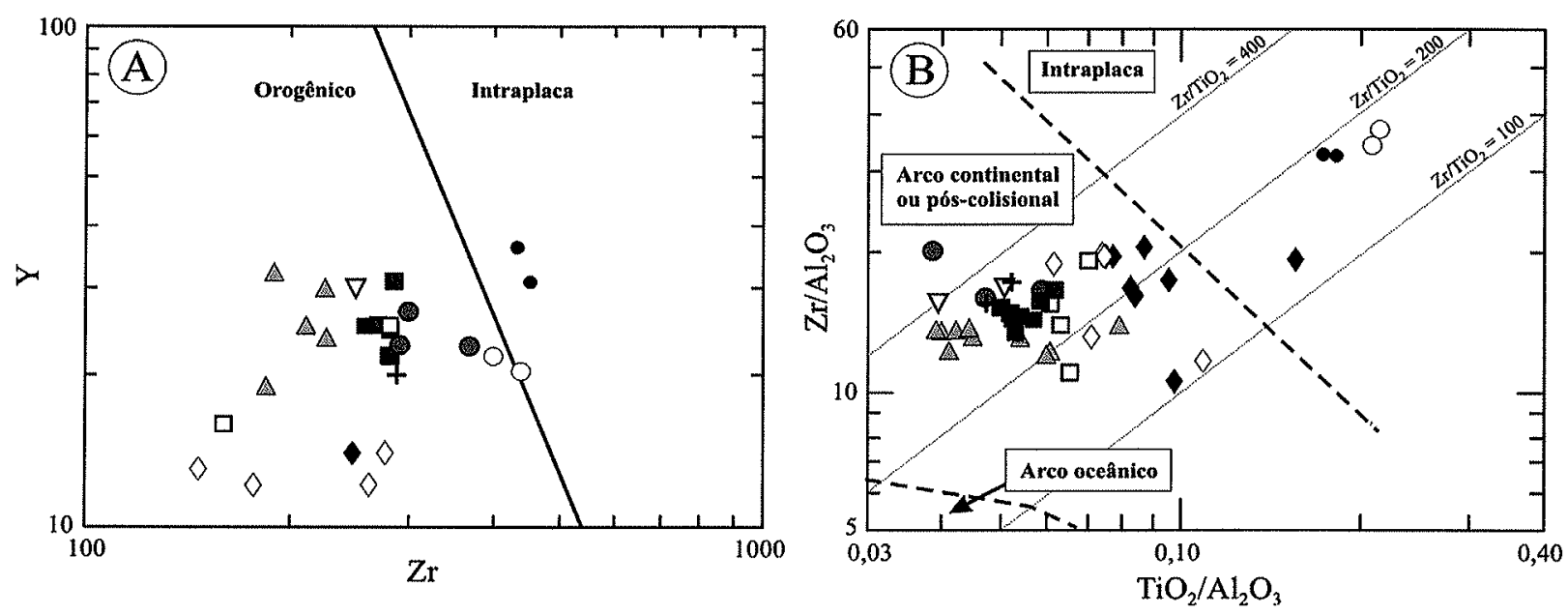

Figura 7 - Diagramas discriminantes, segundo Muller \& Groves (1997), para rochas potássicas associados ao CILS (SiO $<$ $62,1 \%, \mathrm{MgO}>2,8 \%$ e $\mathrm{CaO}>3,3 \%$ - base anidra). $\mathrm{A}$ - Y vs. $\mathrm{Zr}$, com a separação dos tipos intraplaca e orogênico. $B-\mathrm{Zr} / \mathrm{Al} \mathrm{O}_{2} \mathrm{O}_{3}$ vs. $\mathrm{TiO}_{2} / \mathrm{Al}_{2} \mathrm{O}_{3}$, incluindo a separação entre os tipos de arcos continentais e oceânicos. Quadrados preto e cinza respectivamente para unidades 1 e 2 dos traquiandesitos; demais simbolos como na figura 6.

correlação linear Sr-Zr (Fig. 9G). Contudo, relação similar nem sempre é válida para outros traços. Nas efusivas 1 , o comportamento dos traços, $\mathrm{Rb}, \mathrm{Sr}, \mathrm{Ba}$ e $\mathrm{Zr}$, é consistente com o fracionamento mineral (Fig. 9). Assim, as diferenças químicas entre as unidades efusivas podem ser atribuídas à intensidade de eventos pós-cristalização, a desequilíbrios decorrentes da desvolatilização-descompressão, bem como a processos de mistura de mag- mas. Porém, estes processos seriam insuficientes para explicar o conteúdo mais alto de $\mathrm{Sr}$ dos traquiandesitos relativo ao trend de fracionamento do magma TAB (Figs. $9 \mathrm{C} \mathrm{e} \mathrm{E}$ ). Os padrões de elementos incompatíveis e de ETR de espessartitos e traquiandesitos corroboram, em linhas gerais, o vínculo genético com esse magma (Figs. 10C e E). Contudo, os padrões de ETR de ambos são menos fracionados, devido ao maior conteúdo de ETRM e 


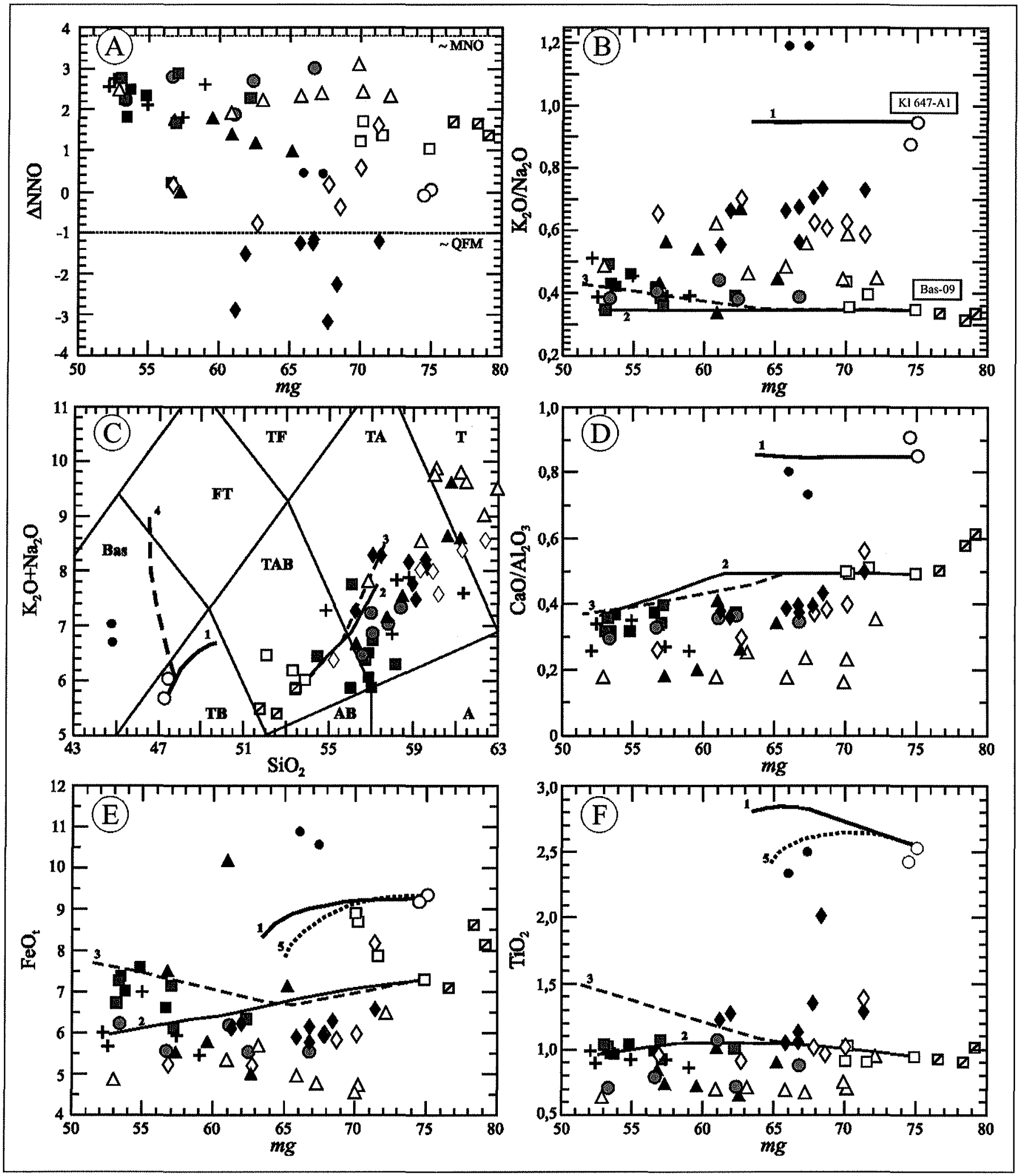

Figura 8 - Variações composicionais de rochas básicas e intermediárias associadas ao CILS (mg $>52 \%$ e SiO, $\leq 63 \%$ - base anidra). $A-\triangle N N O$ vs. $m g$, em que $\triangle N N O=\log f O_{2}{ }^{R T}-\log f O{ }_{2}^{N N O}$ para a mesma temperatura. Valores calculados segundo Moore et al. (1995) e Righter \& Carmichael (1996), considerando $1150^{\circ} \mathrm{C}$-minetes, $1100^{\circ} \mathrm{C}$ - traquiandesito basáltico e MAJ, e $1000^{\circ} \mathrm{C}$ - traquiandesito e espessartito. Oxy-buffers de acordo com compilação apresentada por Frost (1991). $\mathrm{B}-\mathrm{K}_{2} \mathrm{O} / \mathrm{Na}_{2} \mathrm{O}$ vs. mg (ambos em \% mol.). $\mathrm{C}-\mathrm{K}_{2} \mathrm{O}+\mathrm{Na}_{2} \mathrm{O}$ vs. $\mathrm{SiO}$, campos como na figura $6 \mathrm{~A}$. D-E-F-CaO/Al $\mathrm{O}_{3}$, $\mathrm{FeO}$ e $\mathrm{TiO}$, vs. mg respectivamente. Linhas de descenso, em B-F, foram calculadas pelo programa Melts (Ghiorso \& Sack 1995, Asimov \& Ghiorso 1998), para duas amostras consideradas como magmas primitivos. Ol-minete (Kl 647A-1)-diferentes proporções de Ol+Cpx+Cr-Fe óxido: 1 -saturação em $\mathrm{H}_{2} \mathrm{O}, 1$ e $8 \mathrm{kbar}(B-D) ; 4$ - anidro e $8 \mathrm{kbar}(C) ;$ e 5 - saturação em $\mathrm{H}_{2} \mathrm{O}$ e $8 \mathrm{kbar}(E-F)$; e traquiandesito basáltico (Bas-09): 2 e 3 - 1 kbar e, respectivamente, saturação em $\mathrm{H}_{2} \mathrm{O}(\mathrm{Ol}+\mathrm{Cr}-\mathrm{Fe}$ óxido $+\mathrm{Cpx})$ e anidra $(\mathrm{Cr}-\mathrm{Fe}$ óxido $+\mathrm{Ol}+\mathrm{Aug}+$ pigeonita $+\mathrm{Pl})$. Triângulos pretos e brancos para espessartitos com $\triangle N N O<2$ e $\geq 2$, como discriminados em A; quadrados pretos e cinza como na figura 7 , e demais simbolos como na figura 6. 


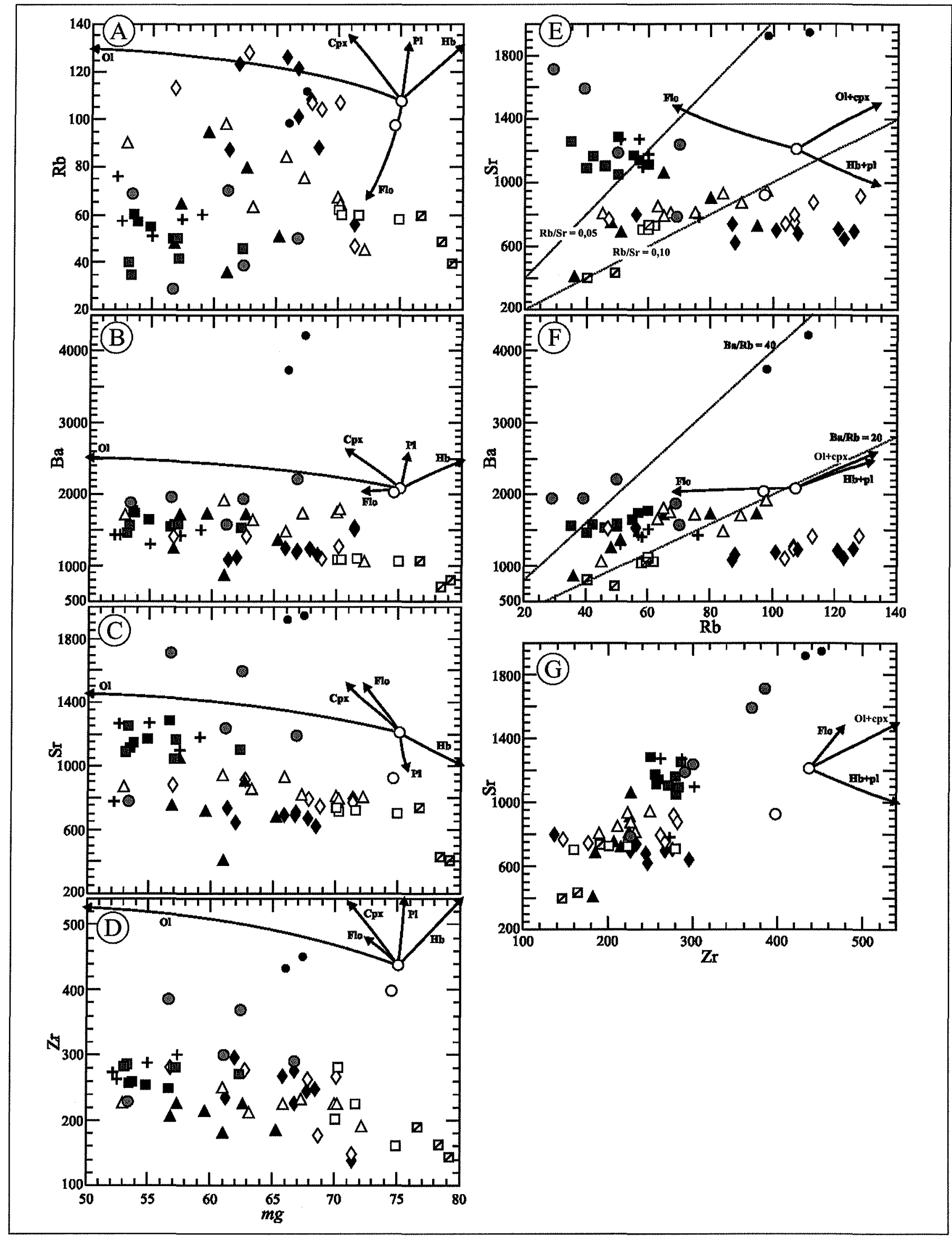

Figura 9-Comportamento de alguns elementos traços em rochas básicas e intermediárias associadas ao CILS (mg $>52 \%$ e $\mathrm{SiO}, \leq$ $63 \%$ - base anidra). A-D - Rb, Ba, Sr e Zr vs. mg. E-F-Sr e Ba vs. Rb. G-Sr vs. Zr. Vetores de fracionamento (até $20 \%$ de cristais) para Ol, Cpx, Pl, hornblenda eflogopita; coeficientes de partição segundo Rollinson (1993); FeO e MgO para Ol e Di do ol-minete, flogopita e K-oligoclásio do minete, e anfibólio do vogesito. Símbolos como nas figuras 6, 7 e 8. 


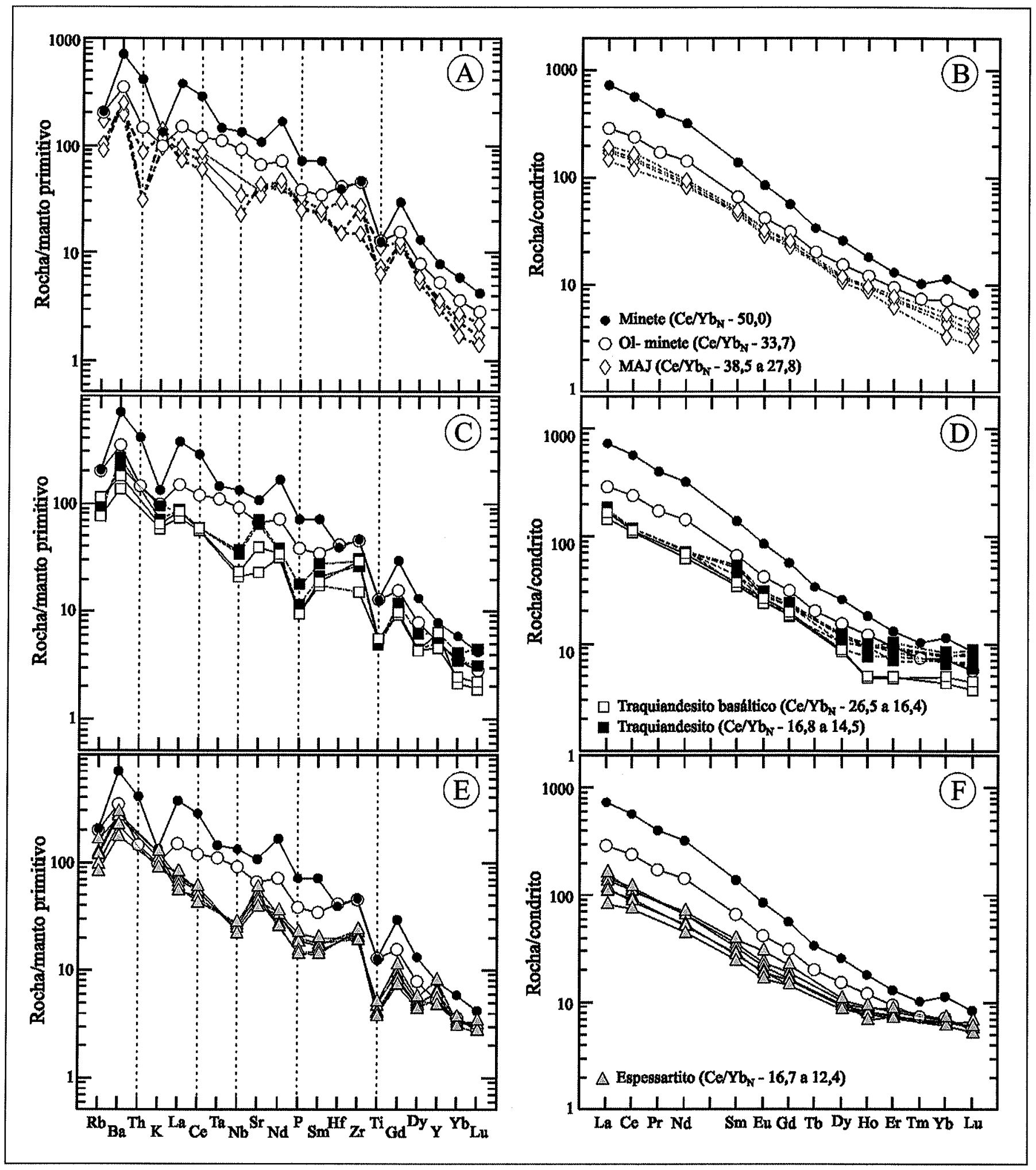

Figura 10 - Diagramas de elementos incompatíveis normalizados para a composição do manto primitivo (Hofmann 1988) e de ETR para a do condrito (Boynton 1984, in Rollinson 1993), respectivamente para: A e B-Minetes e MAJ; C e D - Traquiandesito basáltico e traquiandesito (Lima 1995); E e F-Espessartito (Lima 1995).

ETRP (Figs. 10D e F), e o espessartito exibe também anomalia negativa de $\mathrm{P}$ menos pronunciada. Desta forma, as diferenças químicas entre as lavas cronocorrelatas ao CILS sugerem participação de fontes próximas, mas diversificadas.

GRANITÓIDES Os monzonitos, da mesma forma que BG e $\mathrm{ABM}$, são classificados como granitóides pós-colisionais com a assinatura da subducção (Figs. 11A-B), ou da interação mantocrosta segundo Pearce (1996b). O elevado conteúdo de $\mathrm{Sr}$ e $\mathrm{Ba}$ (Figs. 12F-G), e a similaridade nos padrões de ETR (Fig. 13A) referendam o vínculo genético destes granitóides com as lavas de afinidade shoshonítica (Lima \& Nardi 1998). Entre os monzonitos, a diferenciação é marcada por crescimento dos álcalis até $65 \% \mathrm{SiO}_{2}$, e posterior decréscimo, também seguido pelos granitos 


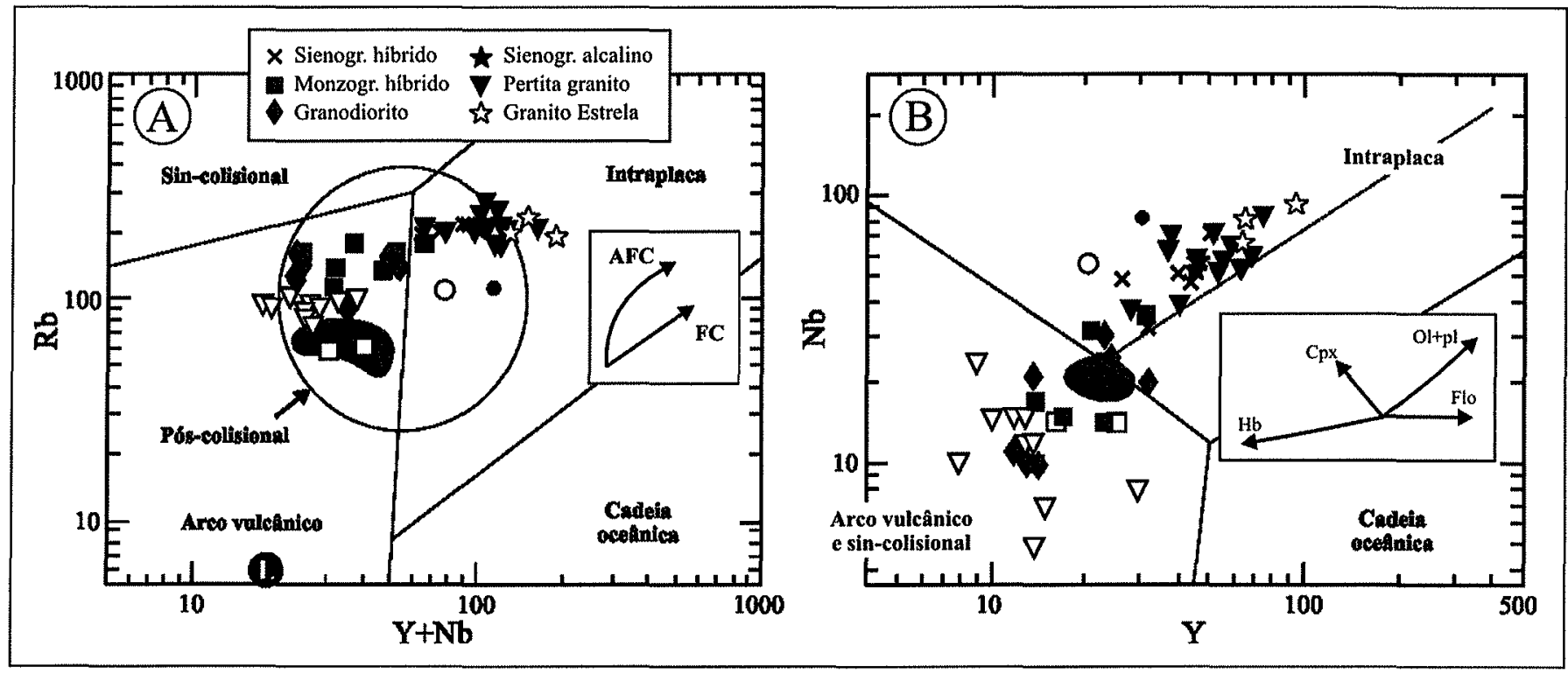

Figura 11 - Diagramas A - Rb vs. $(Y+N b)$, e B - Nb vs. Y (ppm), com a classificação de granitos segundo Pearce et al. (1984) e Pearce (1996b), para os granitóides do CILS. São também plotados, para comparação, traquiandesitos - unidades 1 e 4 (campo cinza), minetes, $e M A J$ com baixa $\mathrm{fO}_{2} ; L$-crosta inferior. Trends: cristalização fracionada-FC e conjunta com assimilação-AFC, segundo Pearce (1996b), e em B, fracionamento de cada fase mineral até 50\%, com Kds segundo Rollinson (1993). Demais símbolos como na figura 6.

do núcleo menos evoluídos (Fig. 6A). A inflexão nesse trend é comumente atribuída ao fracionamento de K-feldspato, porém os demais elementos nem sempre exibem variações consistentes com isto, como exemplificado pelo $\mathrm{Rb}^{\mathrm{A}} \mathrm{Al}_{2} \mathrm{O}_{3}$ (Figs. 11A e 12D).

Com base no comportamento de $\mathrm{CaO}, \mathrm{MgO}, \mathrm{FeO}$ e $\mathrm{TiO}$, (Figs. 12A-D), os monzonitos poderiam ter derivado tanto de traquiandesitos como do MAJ. Os primeiros são preferidos, uma vez que o decréscimo de $\mathrm{Al}_{2} \mathrm{O}_{3}$ e $\mathrm{Sr}$ corrobora o fracionamento preferencial de Pl (Figs. 12E-F). Comparados aos traquiandesitos, contudo, os monzonitos possuem menor ETR e, por vezes, fracionamento mais pronunciado de ETRM (Fig. 13A), o que requer outros processos de diferenciação. Estas rochas, bem como alguns granitos do núcleo, exibem concentrações de $\mathrm{Nb}$ e $\mathrm{Y}$ menor que a dos possíveis parentais traquiandesíticos (Figs. 11A-B), sugerindo a contribuição de fontes pobres em elementos incompatíveis ou o fracionamento de anfibólio. $\mathrm{O} \mathrm{Zr}$ permanece quase constante na transição de traquiandesitos para monzonitos, e forte decréscimo caracteriza a maioria dos granitos do núcleo (Fig. 12H). Trend similar, de constância ou leve decréscimo de $\mathrm{Zr}$ com a diferenciação, caracteriza os granitos tipo I de baixa temperatura, que normalmente envolvem fusão parcial de rochas quartzo-feldspáticas (Chappell 2004). Dentre os granitóides shoshoníticos, o BG exibe os valores mais baixos de $\mathrm{T}_{\mathrm{Zr}}\left(\leq 770^{\circ} \mathrm{C}, \mathrm{Tab} .2\right)$, e está mais próximo dos granitos de baixa temperatura (Miller et al. 2003).

A distinção entre os dois grupos de granitos do CILS é evidenciada pelo comportamento de elementos traços, como proposto por Nardi (1984). Os termos do núcleo são álcali-cálcicos, e o PG evoluiu até composições fracamente peralcalinas, com acmita normativa ( $\leq 1 \%$ ). Todos são classificados como granitos pós-colisionais (Fig. 11), segundo Pearce (1996b). Os termos alcalinos (BAS e PG) e o sienogranito híbrido plotam no campo de granitos intraplaca, e os demais no de granitos de arco vulcânico. Os contrastes entre granodiorito-monzogranito (BG-ABM) e granitos alcalinos são marcantes quanto ao comportamento dos álcalis (Fig. 6A), de $\mathrm{MgO}, \mathrm{CaO}$ e $\mathrm{Al}_{2} \mathrm{O}_{3}$ (Fig. 12A,C, E), de $\mathrm{Sr}, \mathrm{Ba}$ e Rb (Figs. 12 F-H) e de ETR (Fig. 13B-D). Aqueles do núcleo exibem grande dispersão de alguns elementos maiores e traços para pequena variação de $\mathrm{SiO}_{2}$ (Fig. 12). Os padrões de ETR destes são similares entre si, porém marcados por crescimento de ETRL e constância de Eu, na maioria das amostras, o que enfraquece a hipótese de fracionamento de plagioclásio. Além disso, trends superpostos para $\mathrm{TiO}_{2}$ e $\mathrm{FeO}$, como discutido em Gastal et al. (2006b), sugerem evoluções distintas para os dois tipos do núcleo ( $\mathrm{BG}$ e $\mathrm{ABM}$ ). $\mathrm{O}$ sienogranito híbrido exibe valores intermediários de $\mathrm{CaO}, \mathrm{P}_{2} \mathrm{O}_{5}, \mathrm{Rb}, \mathrm{Ba}, \mathrm{Sr}$, porém as concentrações de $\mathrm{Zr}, \mathrm{Nb}, \mathrm{Y}$ e ETRL são mais elevadas e similares as dos tipos alcalinos (Tab. 2). Os últimos, ao contrário, exibem variações químicas regulares e consistentes com o fracionamento mineral, marcadas por decréscimo de $\mathrm{MgO}, \mathrm{FeO}, \mathrm{CaO}, \mathrm{TiO}_{2}$, $\mathrm{Al}_{2} \mathrm{O}_{3}, \mathrm{Sr}, \mathrm{Ba}$ e Eu, e crescimento de $\mathrm{Nb}, \mathrm{Y}, \mathrm{Zr}$ e ETRL (Figs. 11-13). O granito Estrela exibe geoquímica consistente com os tipos alcalinos do CILS, referendando conclusões prévias. O padrão de ETR dos granitos alcalinos descarta a evolução a partir de magma similar ao MAJ, porém é possivel sugerir que derivaram de magma produzido por maior grau de fusão de fonte similar a do ol-minete (Figs. 10B-13D).

Isótopos de $\mathbf{P b}-\mathbf{N d}-\mathrm{Sr}$ Dados isotópicos de $\mathrm{Nd}-\mathrm{Sr}$ para amostras do MAJ e minetes são apresentados na tabela 3. As razões isotópicas de $\mathrm{Pb}$ comum para feldspatos de granitóides do CILS e RT dos minetes estão, respectivamente, nas tabelas 4 e 5 . Procedimentos analíticos conforme Oliveira et al. (2001) e Rodrigues (1992). São também utilizados dados isotópicos $\mathrm{Sr}-\mathrm{Nd}-\mathrm{Pb}$ compilados para granitos do CILS, traquiandesitos e espessartito (Soliani Jr. 1986, Babinski et al. 1996, Remus et al. 2000, Chemale Jr. et al., em preparação), bem como os de metabasalto do Ofiolito Cerro Mantiqueira-OCM (Leite 1997). O último corresponde a basalto de arcos de ilha formado durante a orogênese São Gabriel (900-700 Ma). As diferenças nas razões isotópicas iniciais do $\mathrm{Pb}$ desta rocha devido à idade mais antiga $(\sim 733 \mathrm{Ma})$, relativa ao CILS (604-586 Ma), não foram consideradas.

Razões ${ }^{87} \mathrm{Sr} /{ }^{86} \mathrm{Sr}$ iniciais elevadas e baixo $\varepsilon_{\mathrm{Nd}}(\mathrm{t})$, respectivamente 0,7054 e $-4,0$ a $-3,5$, caracterizam MAJ e minete, enquanto o ol-minete exibe menor $\mathrm{I}_{\mathrm{Sr}}$ e maior $\varepsilon_{\mathrm{Nd}}(\mathrm{t})$ (Tab. 3). Os valores de $T_{D M}$ variam de $1,4-1,5 \mathrm{Ga}$ nos diques a $1,6 \mathrm{Ga}$ no 


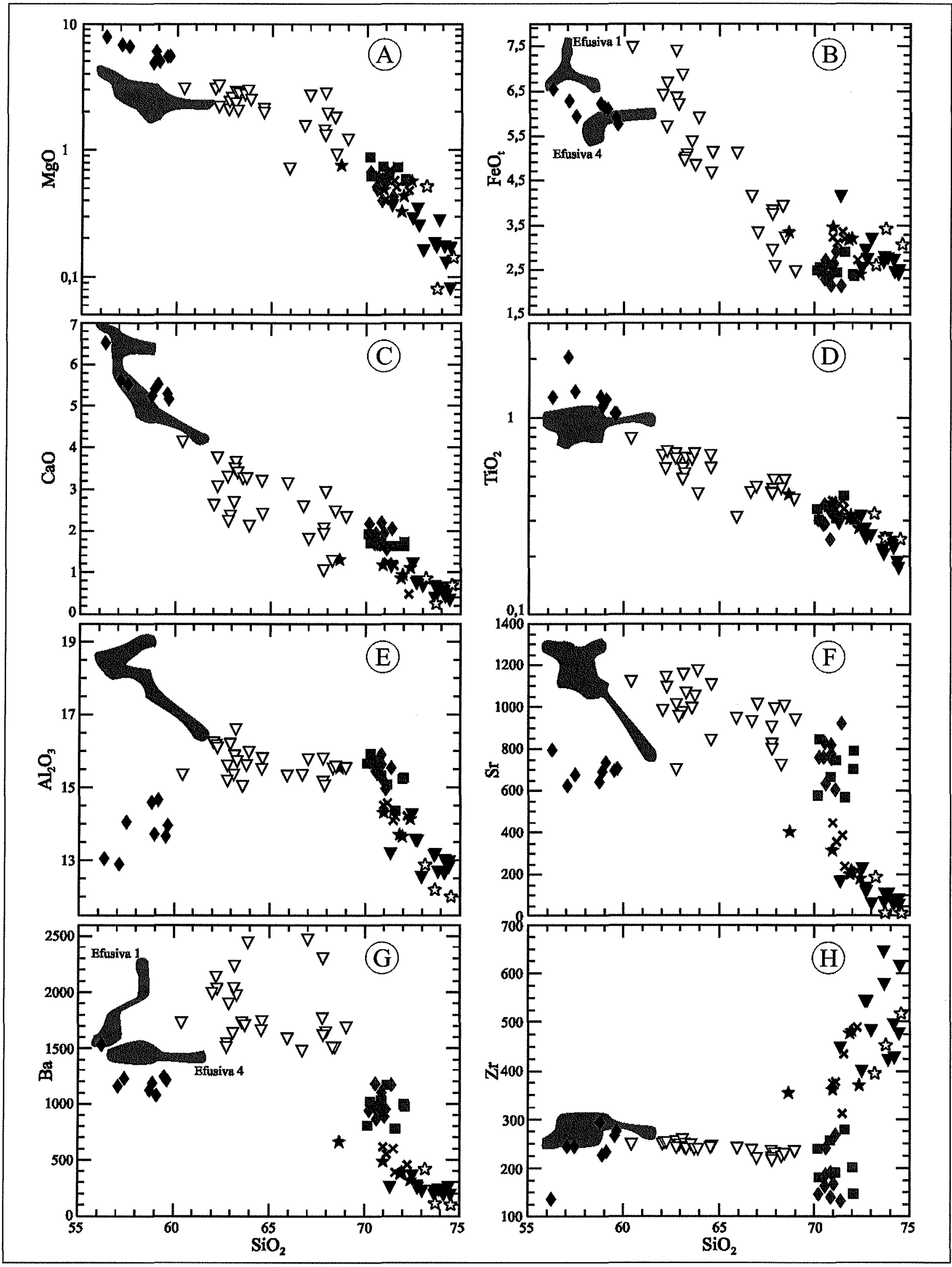

Figura 12 - Diagramas Harker para alguns elementos maiores e traços de granitóides do CILS. $\mathrm{A}-\mathrm{MgO}, \mathrm{B}-\mathrm{FeO}, \mathrm{C}-\mathrm{CaO}, \mathrm{D}$ - $\mathrm{TiO}_{2}, \mathrm{E}-\mathrm{Al}_{2} \mathrm{O}_{3}, \mathrm{~F}-\mathrm{Sr}, \mathrm{G}-\mathrm{Ba}$ e $\mathrm{H}-\mathrm{Zr}$. São também mostrados monzodioritos (MAJ) com baixa fO ${ }_{2}$, e tranquiandesitos (unidades 1 e 4-campo cinza); demais símbolos como nas figuras 6 e 11 . 


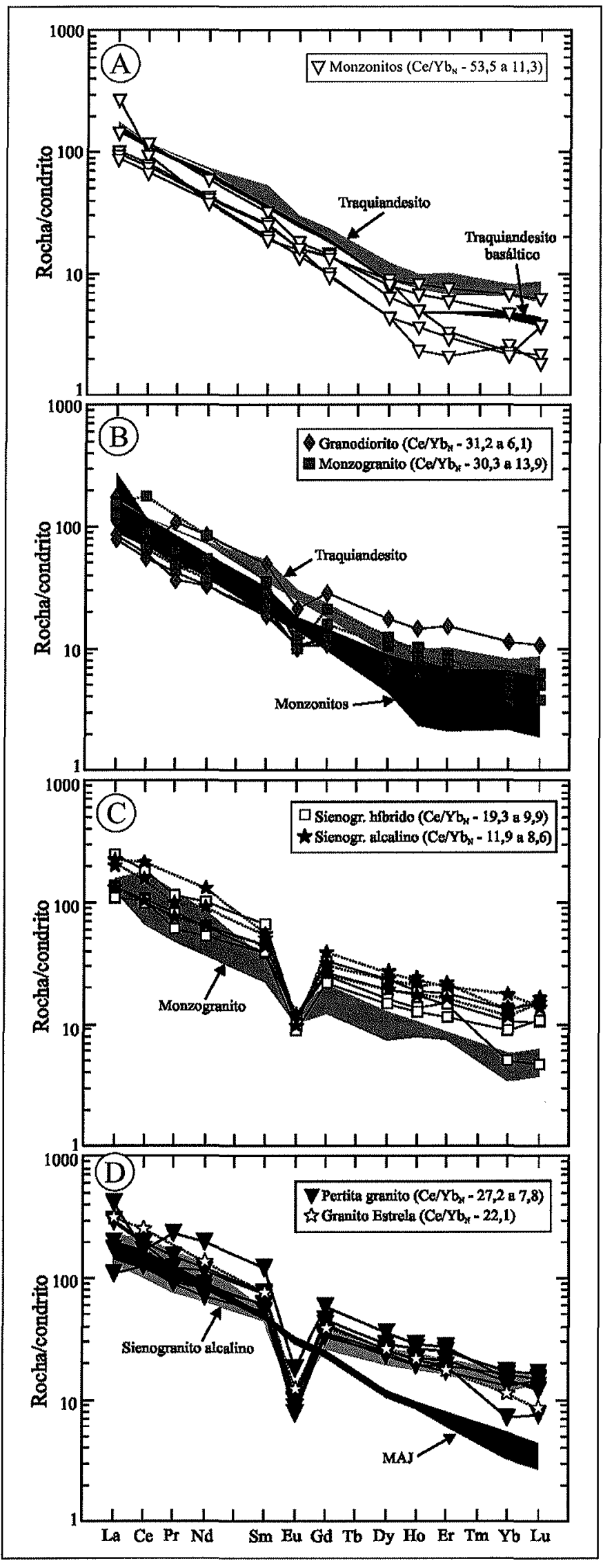

Figura 13 - Diagramas de elementos terras raras - ETR normalizados para a composição do condrito (Boynton 1984, in Rollinson 1993), para granitóides do CILS comparados a rochas relacionadas, respectivamente: $A$-monzonitos, $B$ - granodioritos e monzogranitos do núcleo, $C$-sienogranitos hibridos e alcalinos, $D$-pertita granito e granito Estrela.
MAJ. Comparados aos granitos do CILS, estas rochas exibem maior $\mathrm{I}_{\mathrm{Sr}}$ e $\varepsilon_{\mathrm{Nd}}(\mathrm{t})$ similar ou inferior, como também evidenciado em diagrama de evolução isotópica $\mathrm{Sr}-\mathrm{Nd}$ para a idade de 597 $\mathrm{Ma}$ (Fig. 14A). Em parte, as baixas razões ${ }^{87} \mathrm{Sr} /{ }^{86} \mathrm{Sr}(597 \mathrm{Ma})$ dos granitos alcalinos podem ser atribuídas a distúrbios no sistema isotópico $\mathrm{Rb}$-Sr decorrentes da atividade de fases fluidas tardi a pós-magmáticas (Gastal \& Lafon 1998). Uma das amostras de traquiandesito exibe razões isotópicas $\mathrm{Sr}-\mathrm{Nd}$ similares as dos granitóides e minetes, porém a outra amostra e a de espessartito divergem. Essas exibem baixo $\varepsilon_{\mathrm{Nd}}(597 \mathrm{Ma})$ e $\mathrm{T}_{\mathrm{DM}}$ mais antiga ( $\sim \mathrm{Ga}$ ), o que sugere contribuição de componentes infracrustais paleoproterozóicos. Exceto essas vulcânicas e os granitos alcalinos, as demais amostras definem trend desviado da linha mantélica, indicando a participação de dois tipos de materiais fonte. Um componente tem assinatura isotópica de fonte DM, pobre em elementos incompatíveis e com alta razão $\mathrm{Sm} / \mathrm{Nd}$. Este teria sido gerado durante a orogênese São Gabriel, equivalendo à cunha do manto similar a que originou os metabasaltos-OCM. O outro componente seria o manto rico em elementos incompatíveis, com baixa razão $\mathrm{Sm} / \mathrm{Nd}$ e maior tempo de residência, responsável pela geração do minete.

Minete e ol-minete possuem alta razão ${ }^{207} \mathrm{~Pb} /{ }^{204} \mathrm{~Pb}_{\mathrm{i}}(15,47$ $15,56)$ e variável ${ }^{208} \mathrm{~Pb} /{ }^{204} \mathrm{~Pb}_{\mathrm{i}}(36,71-38,13) \mathrm{e}^{206} \mathrm{~Pb} / 204 \mathrm{~Pb}$ (16,5417,49) (Tab. 5). Tais razões são consistentes com a evolução de um manto com $\mu\left({ }^{238} \mathrm{U} /{ }^{204} \mathrm{~Pb}\right)$ similar ao de um orógeno (Fig. $14 \mathrm{~B}$ ), porém mais toriogênico (Fig. 14C). Razão ${ }^{206} \mathrm{~Pb} / 204 \mathrm{~Pb}$. similar a do metabasalto-OCM e valores de $\mu$ e $\kappa\left({ }^{232} \mathrm{Th} / 238 \mathrm{U}\right)$ mais elevados, ambos sugerem que o ol-minete derivou da cunha do manto astenosférico modificado por fluidos oriundos da placa subductada durante a orogênese São Gabriel. No entanto, um componente do manto enriquecido com maior tempo de residência é requerido para derivar o magma minete, que tem menor razão ${ }^{206} \mathrm{~Pb} / 204 \mathrm{~Pb}$ (Figs. 14B-C) e maior ${ }^{207} \mathrm{~Pb} / 206 \mathrm{~Pb}$ $(0,9351)$. Descarta-se o envolvimento de segmentos crustais mais antigos, nesse caso, uma vez que o extremo enriquecimento em elementos incompatíveis no minete não pode ser decorrente apenas de contaminação ou assimilação. Granitóides do CILS e traquiandesitos exibem razões isotópicas iniciais do $\mathrm{Pb}$ similares, e intermediárias entre as de ol-minete e metabasaltoOCM (Figs. 14B-C), indicando a mistura dos dois componentes da cunha do manto astenosférico, distintos quanto ao enriquecimento em elementos incompatíveis. Granitos do núcleo, traquiandesitos, e piritas de zonas mineralizadas, todos exibem baixa razão ${ }^{207} \mathrm{~Pb} /{ }^{204} \mathrm{~Pb}$ similar a de metabasalto-OCM, porém as razões ${ }^{206} \mathrm{~Pb} /{ }^{204} \mathrm{~Pb}$ decrescem, registrando a contribuição de componente mais antigo e similar ao do minete.

\section{MAGMAS PARENTAIS DO COMPLEXO INTRUSIVO}

Dois grupos de rochas básico-intermediárias, distintos quanto à alcalinidade e razão $\mathrm{K}_{2} \mathrm{O} / \mathrm{Na}_{2} \mathrm{O}(\%$ mol.), estão associados à formação do CILS. Minete e ol-minete são rochas alcalinas potássicas, enquanto as vulcânicas (TAB e traquiandesitos), espessartitos e MAJ, todos são relacionados à série shoshonítica. A mineralogia nas primeiras registra pequena modificação em processos crustais e, ao contrário, a natureza mais evoluída das rochas saturadas reflete a extensiva diferenciação a nível crustal. Em cada grupo, as rochas guardam similaridades nos padrões de elementos incompatíveis e ETR, porém as diferenças existentes sugerem particularidades na gênese e evoluções independentes. Isto é válido mesmo entre os dois minetes, e entre as unidades de traquiandesitos (efusivas 1 a 4 ).

A geração dos dois grupos envolveu, pelo menos, três componentes como sugerem os isótopos de $\mathrm{Sr}-\mathrm{Nd}-\mathrm{Pb}$ (Fig. 14): (1) segmentos infracrustais de idade paleoproterozóica ou superior; (2) componente derivado da cunha do manto, produzida durante a orogênese São Gabriel (900-700 Ma); e (3) componentes do 
Tabela 3 - Resultados isotópicos Sr-Nd do monzodiorito Arroio do Jacques e minetes, complexo intrusivo Lavras do Sul.

\begin{tabular}{|c|c|c|c|c|c|c|c|c|c|c|c|c|c|}
\hline Amostra & $\mathbf{R b}$ & $\mathbf{S r}$ & $\mathbf{R b} / \mathbf{S r}$ & ${ }^{87} \mathrm{Rb} /{ }^{86} \operatorname{Sr}(2 \sigma)$ & ${ }^{87} \mathrm{Sr} /{ }^{86} \mathrm{Sr}(2 \sigma)$ & $\mathbf{I S r}^{*}$ & Sm & Nd & $\mathrm{Sm} / \mathrm{Nd}$ & ${ }^{147} \mathrm{Sm} /{ }^{1 / 4} \mathrm{Nd}(1 \sigma)$ & ${ }^{143} \mathrm{Nd} /{ }^{144} \mathrm{Nd}(1 \sigma)$ & $\varepsilon_{\mathrm{Nd}}(t)^{*}$ & $\begin{array}{l}T_{\mathrm{DM}} \\
\text { (Ga) }\end{array}$ \\
\hline \multicolumn{14}{|c|}{ 1. Monzodiorito Arroio do Jacques } \\
\hline K1 411 & 116,9 & 916,7 & 0,128 & $0,369(11)$ & $0,708596(048)$ & 0,705444 & 8,54 & 47,83 & 0,179 & $0,10790(15)$ & $0,512068(10)$ & $-4,33$ & 1,57 \\
\hline KJ 88 & 58,2 & 949,9 & 0,061 & $0,177(05)$ & $0,706873(148)$ & 0,705361 & 9,37 & 47,83 & 0,196 & $0,11844(11)$ & $0,512153(07)$ & $-3,48$ & 1,61 \\
\hline \multicolumn{14}{|c|}{ 2. Diques de minetes } \\
\hline K1647E-2 & 99,56 & 1742 & 0,057 & $0,165(02)$ & $0,706841(090)$ & 0,705453 & 25,67 & 159,25 & 0,161 & $0,09743(90)$ & $0,512029(16)$ & $-4,41$ & 1,48 \\
\hline K1647A-1 & 96,79 & 979 & 0,099 & $0,286(04)$ & $0,707143(110)$ & 0,704737 & 13,16 & 77,09 & 0,171 & $0,10324(40)$ & $0,512149(11)$ & $-2,50$ & 1,39 \\
\hline
\end{tabular}

Tabela 4 - Isótopos de Pb para feldspatos de granitóides do complexo intrusivo Lavras do Sul.

\begin{tabular}{|lccccccc|}
\hline \multicolumn{10}{|c|}{ Amostra } & ${ }^{206} \mathbf{P b} /{ }^{\mathbf{2 0 4}} \mathbf{P b}$ & $\sigma$ & ${ }^{207} \mathbf{P b} /{ }^{\mathbf{2 0 4}} \mathbf{P b}$ & $\sigma$ & ${ }^{208} \mathbf{P b} /{ }^{\mathbf{2 0 4}} \mathbf{P b}$ & $\sigma$ \\
\hline K1 109 pertita granito & 17,605 & 0,011 & 15,527 & 0,014 & 37,493 & 0,045 \\
K1 405 sienogranito alcalino & 17,459 & 0,010 & 15,508 & 0,014 & 37,348 & 0,044 \\
K1 159 monzonito (MT) & 17,558 & 0,010 & 15,542 & 0,014 & 37,486 & 0,045 \\
K1 97 monzodionito (MAJ) & 17,512 & 0,013 & 15,548 & 0,016 & 37,509 & 0,046 \\
\hline Notas: Razões isotópicas corrigidas para o fracionamento de massa por um fator de $0,12 \pm 0,03$ per a.m.u. & \\
\hline
\end{tabular}

Tabela 5-Composição isotópica do Pb e concentrações de U, Th, Pb de minetes, complexo intrusivo Lavras do Sul.

\begin{tabular}{|c|c|c|c|c|c|c|c|c|c|}
\hline \multirow[b]{2}{*}{ Sample } & \multicolumn{3}{|c|}{ Razões medidas $(1 \sigma)$} & \multicolumn{3}{|c|}{ ppm } & \multicolumn{3}{|c|}{ Razões iniciais } \\
\hline & ${ }^{206} \mathrm{~Pb} /{ }^{204} \mathrm{~Pb}$ & ${ }^{207} \mathbf{P b} /{ }^{204} \mathbf{P b}$ & ${ }^{208} \mathrm{~Pb} /{ }^{204} \mathrm{~Pb}$ & $\mathbf{U}$ & Th & $\mathbf{P b}$ & ${ }^{206} \mathrm{~Pb} /{ }^{204} \mathrm{~Pb}$ & ${ }^{207} \mathrm{~Pb} /{ }^{204} \mathrm{~Pb}$ & ${ }^{208} \mathbf{P b} /{ }^{204} \mathbf{P b}$ \\
\hline $647 \mathrm{E}-1$ minete & $20,797(12)$ & $15,720(14)$ & $42,534(51)$ & 7,7 & 33 & 12 & 16,541 & 15,466 & 36,709 \\
\hline $647 \mathrm{~A}-1$ olivina minete & $19,278(11)$ & $15,670(14)$ & $39,952(48)$ & 3,7 & 11,8 & 13 & 17,488 & 15,563 & 38,129 \\
\hline
\end{tabular}

manto diversificadamente enriquecidos em elementos incompatíveis. Estes últimos poderiam ter sido originados, em parte, durante a orogênese São Gabriel, como indicam os isótopos de $\mathrm{Pb}$ dos minetes (Figs. 14B-C). Contudo, Gastal et al. (2005) argumentaram que estas rochas derivaram do manto litosférico previamente modificado em eventos de subducção paleoproterozóicos e posteriormente re-enriquecido no Neoproterozóico, via adição de líquidos (metasomatismo do tipo OIB). A geração dos dois magmas minetes a partir de segmentos em diferentes profundidades é uma explicação viável consistente com o indicado pela composição do diopsídio (Fig. 2B). A assinatura química da subducção é mais acentuada em traquiandesitos e TAB (Fig. 10), porém a maior variação no conteúdo de ETRP e ETRM nessas rochas seria mais facilmente explicada pela interação manto/crosta. Entre as unidades de traquiandesitos, a diversidade química resultou de processos crustais incluindo a interação com magma minete. $\mathrm{O}$ contraste nos teores de $\mathrm{Sr}$ relativo ao magma TAB (Figs. $9 \mathrm{C}$ e E) seria um indicativo de que os traquiandesitos derivaram de magma parental distinto. Contudo, os dados isotópicos são insuficientes para uma conclusão definitiva.

Com base nos diagramas de variação (Figs. 8 e 9), espes- sartito e MAJ são as rochas que melhor se encaixam como fracionados do TAB, porém também tiveram evoluções independentes e interagiram com materiais diversos, como sugerem os padrões de elementos incompatíveis e ETR (Fig. 10). O espessartito pode representar diferenciado hidratado do magma TAB, equilibrado a maior pressão, o que está de acordo com o indicativo da composição do piroxênio (Figs. 2B-C) e resultados experimentais (Barclay \& Carmichael 2004). Contudo, nenhuma das soluções de fracionamento, obtida para a amostra do TAB (Bas 09) pelo Melts, aponta o equilíbrio do anfibólio. Resultado contrário foi obtido para a associação TAB-MAJ, sendo as diferenças explicadas pelas condições de saturação em $\mathrm{H}_{2} \mathrm{O}$, anidra no MAJ e próximas à saturação no TAB. A ausência de olivina no MAJ implica em pressões $\geq 3 \mathrm{kbar}$ e, em ambos, a biotita é estável a baixa temperatura $\left(<930^{\circ} \mathrm{C}\right)$, em condições de saturação em $\mathrm{H}_{2} \mathrm{O}$ e pressão superior a $3 \mathrm{kbar}$. A interação do MAJ com líquido derivado de um dos minetes explicaria a presença de Mg-biotita magmática, e a natureza geoquímica particular como concentrações elevadas de $\mathrm{TiO}_{2}, \mathrm{P}_{2} \mathrm{O}_{5}, \mathrm{Rb}$ e $\mathrm{K}_{2} \mathrm{O}$ (Figs. 8 e 9). Deste modo, o MAJ parece resultar da interação de líquidos distintos em câmara magmática de epizona ( $\approx 3 \mathrm{kbar}$ ), provavelmente via infiltração do magma ol-minete/minete em 


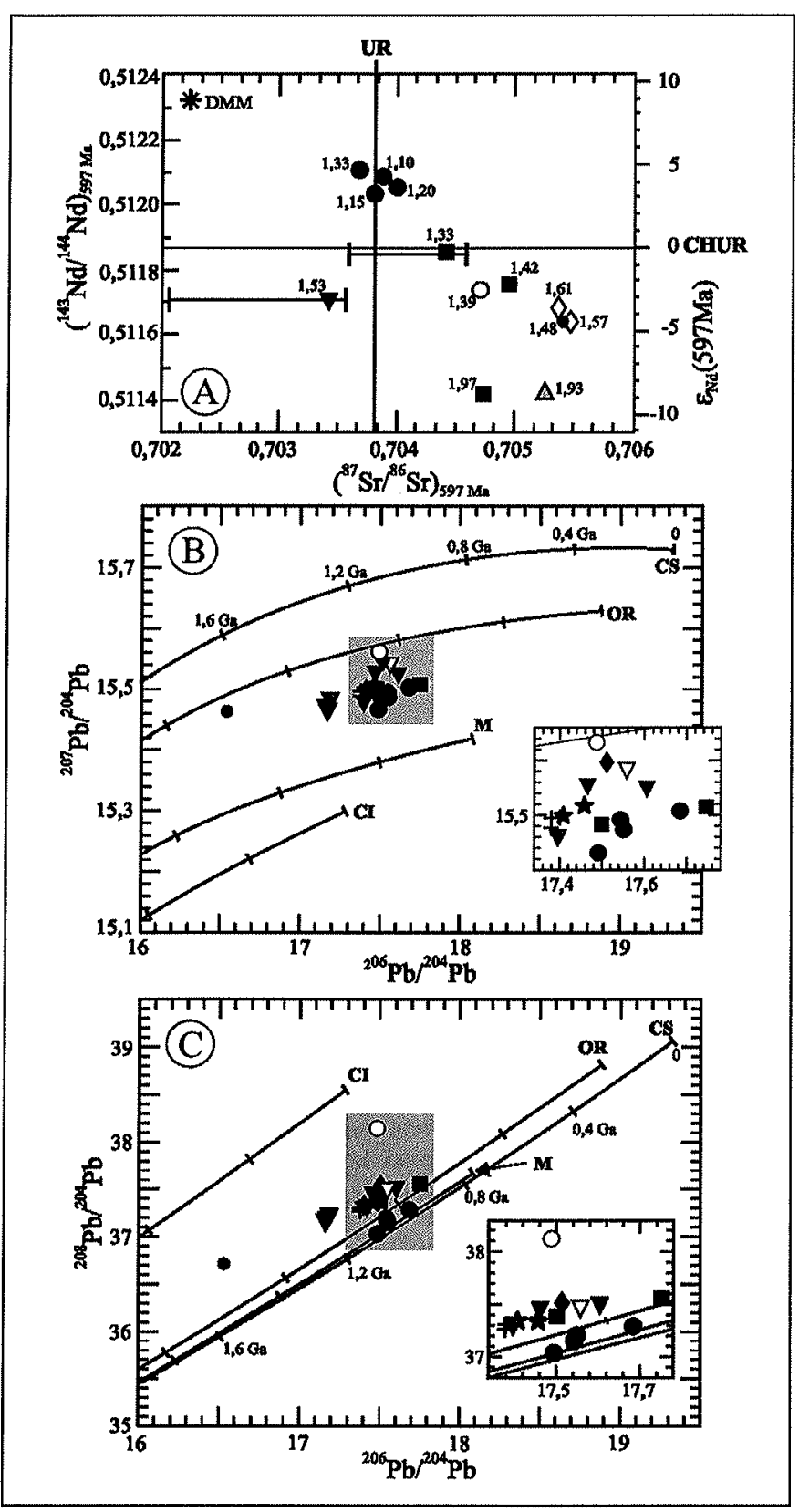

Figura 14-A-Diagrama de correlação isotópica Sr-Nd, para a idade intermediária de $597 \mathrm{Ma}$, de monzodioritos (MAJ) e minetes, granitos (Babinski et al. 1996, Soliani Jr. 1986), traquiandesitos e espessartito (Chemale Jr. et al. em preparação). Também inclui metabasaltos do Ofiolito Cerro Mantiqueira (Leite 1997). Para os granitos é realçado o intervalo de ${ }^{87} \mathrm{Sr} /{ }^{86} \mathrm{Sr}(597 \mathrm{Ma})$ das amostras estudadas por Soliani Jr. (1986). Números correspondem às idades modelos $T_{D M}(N d)$, em $G a$, para cada amostra. $B$ e C-Diagramas exibindo a evolução isotópica do $\mathrm{Pb}-\mathrm{Plum}$ botectonics version I (Doe \& Zartmann 1979), respectivamente, ${ }^{207} \mathrm{~Pb}{ }^{204} \mathrm{~Pb} e^{208} \mathrm{~Pb}{ }^{204} \mathrm{~Pb}$ vs. ${ }^{206} \mathrm{~Pb}{ }^{204} \mathrm{~Pb}$, para feldspatos de granitóides do CILS, e de traquiandesitos Hilário (Remus et al. 2000) e metabasaltos-OCM (Leite 1997). São também incluidas as razões isotópicas iniciais do Pb calculadas para os minetes, e aquelas de piritas de ocorrências de Au no CILS e vulcânicas encaixantes (Remus et al. 2000). Säo mostradas as curvas de evolução do Pb para os principais reservatórios (intervalos de 0,4 Ga): $C I-$ crosta inferior, $C S$ - crosta superior, $O R$ - orógeno e $M$ - manto. Círculos cinza para metabasaltos-OCM, quadrados cinza para traquiandesitos, triângulos invertidos cinza para piritas; e em B$C$, cruzes para granitos do núcleo; demais símbolos como nas figuras 6 e 11 . um corpo parcialmente cristalizado e derivado do magma TAB desgaseificado.

TIPOS DE GRANITOS A separação dos dois grupos de granitóides do CILS é também evidenciada pela composição de fases máficas (Figs. 3 e 4). Aqueles correlacionados aos traquiandesitos e MAJ, formados durante o principal episódio ígneo $(\approx 600$ $\mathrm{Ma}$, incluem monzonitos (MT e quartzo monzonito associado) e granitos do núcleo (granodiorito-BG e granitos híbridos). Nestes, a composição das fases máficas é homogênea e consistente com a diferenciação, porém revela diferenças na profundidade de posicionamento (Fig. 3B). As variações na composição química da rocha indicam evoluções independentes e derivação a partir de magma parental próximo aos traquiandesitos, envolvendo outros processos de diferenciação (Figs. 11-13). A contaminação/ interação com fusão parcial de granitóides mais antigos (Neoproterozóicos?) é uma hipótese atrativa, fundamentada no comportamento de alguns elementos traços e na baixa $T_{Z R}$ dos tipos do núcleo e monzonitos (Figs. 11B, 12H, 13B, Tab. 2). Os granitos do núcleo representam pulsos distintos que segundo as feições petrográficas, discutidas em Gastal et al. (2006b), registram situações relacionadas a fronts de dissolução/interação de um pulso anterior (monzogranito) por novo pulso de magma dacítico (BG). Esta interação teria ocorrido durante o soeguimento do pluton granítico, de 4,5-4,0 para 2,0-3,0 kbar. A contaminação dos tipos híbridos mais evoluídos (sienogranitos) pelos granitos alcalinos, posicionados ao redor do núcleo, é indicada por contrastes entre a química da rocha e da mineralogia máfica e acessória (Figs. 35,11-13). Os monzonitos (MT) parecem representar pulsos distintos de magmas menos evoluídos, posicionados durante forte gradiente de pressão (4,5-4,0 para 1,0 kbar), o que é consistente com intrusão do tipo cone-sheet (Gastal et al. 2006a). Esta foi formada aparentemente durante ou muito próximo ao periodo de ressurgência no pluton central. Os termos subvulcânicos do MT teriam afetado e soerguido o MAJ, explicando a oxidação de algumas amostras (Figs. 6A e 8A) e as diferenças na composição de anfibólio e biotita deste (Figs. 3 e 4).

Os granitos alcalinos (sienogranito- BAS e pertita granitoPG), bem como o granito Estrela, resultaram da diferenciação, via fracionamento de plagioclásio e clinopiroxênio, de magmas parentais similares, como revelado pela química de rocha e minerais (Figs 3, 4, 11-13). O extremo efeito da diferenciação em anfibólio e biotita dos tipos alcalinos do CILS, paralelo à menor variação na química da rocha, poderia ser mais um indicativo de que o posicionamento destes ocorreu em incrementos, como proposto em Gastal et al. (2006a). Este processo teria ocorrido em níveis crustais mais rasos ( $\leq 2 \mathrm{kbar}$ ), iniciado logo após o posicionamento dos granitóides shoshoníticos, com a formação do BAS $(\approx 598 \mathrm{Ma}$ ), e se prolongado até $\approx 586 \mathrm{Ma}$, que é a idade do PG. O vínculo destes com o magma ol-minete é também sugerido pelos padrões de ETR (Figs. $10 \mathrm{~B}$ e 13D) e $\varepsilon_{\mathrm{Nd}}$ (Fig. 14A). Porém, as razões ${ }^{207} \mathrm{~Pb} /{ }^{204} \mathrm{~Pb}$ e ${ }^{208} \mathrm{~Pb} /{ }^{204} \mathrm{~Pb}$ desses granitos são intermediárias entre as do ol-minete e as das rochas shoshoníticas (Figs. 14B-C), o que parece sugerir que estes também resultaram da interação de dois magmas parentais, com maior contribuição de líquidos derivados do ol-minete.

CONSIDERAÇÕES FINAIS As rochas básico-intermediárias associadas ao CILS foram originadas a partir de segmentos distintos do manto litosférico, com maior contribuição crustal naqueles de filiação shoshonítica. Contudo, todas exibem razões $\mathrm{Ba} /$ La elevadas e equiparáveis a rochas crustais, o que aliado às altas razões $\mathrm{La} / \mathrm{Yb}_{\mathrm{N}}$ sugere que a interação entre fontes ocorreu a nível do manto. Isto permite associar a geração destas rochas a delaminação da litosfera, comum em ambientes pós-colisionais (Gastal et al. 2005). Pode-se especular que a diversidade nos processos 
de enriquecimento do manto litosférico, registradas nos minetes, se deva também a líquidos produzidos por fusão parcial de segmentos crustais delaminados. Isto explicaria os contrastes nas razões isotópicas de $\mathrm{Pb}-\mathrm{Nd}-\mathrm{Sr}$ nos dois, e o maior enriquecimento em elementos incompatíveis no minete. De qualquer modo, estas rochas marcam a mudança no regime tectônico, para condições extensionais, esperadas nesses ambientes.

A geração dos dois grupos de granitóides é similar, porém a contribuição crustal parece ter sido mais importante nos granitos do núcleo, enquanto nos alcalinos teria prevalecido a interação entre líquidos derivados dos dois magmas parentais, TAB-traquiandesitos e ol-minete. Tais processos de interação são também sugeridos em unidades efusivas e evidenciados no MAJ, justificando a existência de diques de lamprófiros mistos (Gastal et al. 2006a). Entre os granitóides, os maiores contrastes nas condições de cristalização ocorreram durante o posicionamento das unidades mais antigas e shoshoníticas $(\approx 600 \mathrm{Ma})$, incluindo mais de um ciclo de subsidência-ressurgência, o que também é evidenciado pelos xenólitos de vulcanoclásticas no monzogranito. Os granitos alcalinos, posicionados possivelmente em incrementos ao redor do pluton central, estariam marcando os períodos finais da ressurgência da câmara magmática.

Agradecimentos Este trabalho foi financiado com os auxílios de pesquisa FAPERGS $n^{\circ}$ 98/0662-1, 00/2366-3, 00/1366-8 e 02/0611-7, e PRONEX/CPGq - IGEO-UFRGS. Agradecemos a contribuição de revisores anônimos, bem como a ajuda e assistência na obtenção de dados analíticos conferida pelo staff dos laboratórios de Geologia Isotópica/CG-UFPA - Pará-Iso e de Microssonda Eletrônica - CPGq/IGEO/ UFRGS. Participaram em diferentes etapas deste trabalho, os colegas bolsistas de iniciação científica Gustavo A. Fernandes (FAPERGS nº 00/51404.4), e João Felipe H. Appollo (PIBIC-CNPq, UFRGS).

\section{Referências}

Anderson, J.L. \& Smith, D.R. 1995. The effects of temperature and 70 on the Al-in-hornblende barometer. Am. Mineral., 80(5/6): 549-559.

Asimov, P.D. \& Ghiorso, M.S. 1998. Algorithmic Modifications Extending MELTS to Calculate Subsolidus Phase Relations. Am. Mineral., 83:1127-1131.

Babinski, M., Chemale Jr., F., Hartmann, L. A., VanSchmus, W. R, Silva, L. C. da., 1996. Juvenile accretion at 750-700Ma in southern Brazil. Geology, 24(5): 439-442.

Barclay, J., Carmichael, I.S.E. 2004. A hornblende basalt from Western Mexico: Water-saturated phase relations constrain a pressure-temperature window of eruptibility. J. Petrol., 45(3):485-506.

Carmichael, I.S.E., Lange, R.A., Luhr, J.F. 1996. Quaternary minettes and associated volcanic rocks of Mascota, western Mexico: a consequence of plate extension above a subduction modifed mantle wedge. Contrib. Mineral. Petrol., 124: 302-333.

Chappell, B.W. 2004. High- and low-temperature granites. The Ishihara Symposium: Granites and Associated Metallogenesis, Geosc. Australia, 35-36.

Deer, W.A.; Howie, R.A., Zussman, J., 1978. Rock-forming Minerals, vol. $2 A$, Single-chain silicates (2nd edition). New York, John Wiley \& Sons, $668 \mathrm{p}$

Doe, B.R.; Zartman, R.E., 1979. Plumbotectonics I, The Phanerozoic In: Barnes, H.L. (Ed.). Geochemistry of Hydrothermal Ore Deposits, $2^{\prime \prime}$ ed., Wiley Interscience, p.22-70.

Foley, S.F., Venturelli, G., Green, D.H., Toscani, L. 1987. The ultrapotassic rocks: Characteristics, classification, and constraints for petrogenetic models. Earth Sci. Rev., 24:81-134.

Frost, B.R. 1991. Introduction to oxygen fugacity and its petrologic importance. In: Lindsley, D.H. (Ed.). Oxide Minerals: Petrologic and Magnetic Significance. Rev. Mineral., 25:1-9.

Gastal, M.C.P. 1998. Suite Intrusiva Saibro, RS: Avaliação de um Modelo Petrológico. Tese de Doutoramento em Geociências, Instituto de Geociências, Universidade Federal do Rio Grande do Sul, 365 p.

Gastal, M. C. P. 2004. Química mineral de granitóides e minetes do Complexo Intrusivo Lavras do Sul, comparada à de rochas vulcâ- nicas cronocorrelatas. In: CPGq/UFRGS, Encontro Dez anos de microssonda eletrônica em Porto Alegre, 1, Resumos expandidos, p. 67-78.

Gastal, M. C. P. \& Lafon, J. M., 1998. Gênese e evolução dos granitóides metaluminosos de afinidade alcalina da porção oeste do Escudo Sul-riograndense: geoquímica e isótopos de $\mathrm{Rb}-\mathrm{Sr}$ e $\mathrm{Pb}-\mathrm{Pb}$. Rev. Bras. Geoc. 28(1), 11-28

Gastal, M. C. P., Lafon, J.M., Hartmann, L., Koester, E. 2005. Sm-Nd isotopic investigation of Neoproterozoic and Cretaceous igneous rocks from southern Brazil: a study of magmatic processes. Lithos, 82:345-377

Gastal, M. C. P., Lafon, J.M., Ferreira, F.J.F., Magro, F.U. S., Remus, M.V.D., Sommer, C.A. 2006a. Reinterpretação do Complexo Intrusivo Lavras do Sul - RS, de acordo com os sistemas vulcano-plutônicos de subsidência. Parte I: Geologia, geofísica e geocronologia $\left({ }^{207} \mathrm{~Pb} / 206 \mathrm{~Pb} \mathrm{e}^{206} \mathrm{~Pb} /{ }^{238} \mathrm{U}\right)$. Rev. Bras. Geoc., no prelo.

Gastal, M. C. P., Fernandes, G. A., Ferreira, F.J.F., Frizzo, R.G. 2006b. Zonalidade reversa dos granitos do Complexo Intrusivo Lavras do Sul, RS: Petrografia, susceptibilidade magnética e óxidos de FeTi. Rev. Bras. Geoc., no prelo.

Ghiorso, M.S. \& Sack, R.O. 1995. Chemical Mass Transfer in Magmatic Processes IV. A revised and internally consistent thermodynamic model for the interpolation and extrapolation of liquid-solid equilibria in magmatic systems at elevated temperatures and pressures. Contrib. Mineral. Petrol., 119:197-212

Grove, T.L. \& Juster, T.C. 1989. Experimental investigations of low-Ca pyroxene stability and olivine-pyroxene-liquid equilibria at $1 \mathrm{~atm}$ in natural basaltic and andesitic liquids. Contrib. Mineral. Petrol., 103:287-305.

Hill, R \& Roeder, P. 1974. The crystallization of spinel from basaltic liquid as a function of oxygen fugacity. $J$. Geol., 82:709-729.

Hofmann, A. W. 1988. Chemical differentiation of the earth: the relationship between mantle, continental crust, and oceanic crust. Earth Planet. Sci. Lett., 90(3), 297-314.

Kowallis, B.J., Christiansen, E.H., Griffin, D.T. 1997. Compositional variations in titanite. Geol. Soc. Am. Abst. with Prog., 29(6):402

Le Maitre, R.W. (Ed.). 1989. A Classification of Igneous rocks and 
Glossary of terms: recommendations of the International Union of Geological Sciences Subcommission on the Systematics of Igneous Rocks.Oxford, Blackwell Scientific Publications, 193p.

Leite, J.A.D. 1997. A origem dos harzburgitos da seqüência Mantiqueiras e implicações tectônicas para o desenvolvimento do Neoproterozóico. Tese de Doutoramento em Geociências, Instituto de Geociências, Universidade Federal do Rio Grande do Sul, 243p.

Lima, E.F. de 1995. Petrologia das rochas vulcânicas e hipoabissais da Associação Shoshonitica de Lavras do Sul, RS. Tese de Doutoramento em Geociências, Instituto de Geociências, Universidade Federal do Rio Grande do Sul, 338p.

Lima, E.F. de \& Nardi, L.V.S. 1991. Os lamprófiros espessartíticos da Associação Shoshonítica de Lavras do Sul, RS. Geochim. Bras., 5(1/2): 117-130.

Lima, E.F. de \& Nardi, L.V.S. 1998. The Lavras do Sul Shoshonitic Association: implications for origin and evolution of Neoproterozoic shoshonitic magmatism in southernmost Brazil. J. South Am. Earth Sci.,11(1):67-77.

Liz, J.D. 2003. Aspectos petrográficos, composicionais e potencialidade para mineralizações de ouro esulfetos do sistema multi-intrusivo da associação shoshonítica de Lavras do Sul (RS), Dissertação de mestrado, Instituto de Geociências, Universidade Federal do Rio Grande do Sul, $127 \mathrm{p}$.

Miller, C.F., McDowell, S.M. \& Mapes, R.W. 2003, Hot and cold granites? Implications of zircon saturation temperatures and preservation of inheritance. Geology, 31: 529-532.

Mitchell, R.H. 1990. A review of the compositional variation of amphiboles in alkaline plutonic complexes. Lithos, 26:135-156.

Moore, G., Righter, K., Carmichael, I.S.E. 1995. The effect of dissolved water on the oxidation state of iron in natural silicate liquids. Contrib. Mineral. Petrol., 120:170-179.

Morimoto, N. (Ed.) 1988. Nomenclature of pyroxenes. Am. Mineral., 73(9/10): $1123-1133$.

Muller, D. \& Groves, D.J. 1997. Potassic Igneous Rocks and Associated Gold-copper Mineralization, $2^{\circ}$ ed.,Springer , 238p.

Nachit, H., Razafimahefa, N., Stussi, J.M., Carron, J.P. 1985. Composition chimique des biotites et typologie magmatique des granitoides. C. R. Acad. Sc. Paris, 11: 813-818.

Nardi, L. V. S. 1984. Geochemistry and Petrology of the Lavras Granite Complex, RS, Brazil. Doctor of Philosophy Thesis, Department of Geology King's College, University of London, 268p.

Oliveira, E.C., Lafon, J.M., Gioia, S.M.L., Pimentel, M.M. 2002. Implantação do método Sm-Nd para minerais metamórficos e sua aplicação em rochas da região central do Amapá, Sudeste do Escudo das Guianas. In: Cong. Brasil. Geol., 41. João Pessoa, SBG, Anais de resumos, p. 502.

Pearce, J. 1996a. A user's guide to basalt discrimination diagrams. In: Wyman, D.A. (Ed.) Trace element geochemistry of volcanic rocks: applications for massive sulphide exploration. Geol. Assoc. Canadá, Short Course Notes, 12, p.79-113.

Pearce, J. 1996b. Sources and settings of granitic rocks. Episodes, 19(4): $120-125$.

Pearce, J.A., Harris, N.B.W., Tindle, A.G. 1984. Trace element diagrams for the tectonic interpretation of granitic rocks. J. Petrol.,
25(4): 956-983.

Perugini, D., Busà, T., Poli, G., Nazzareni, S. 2003. The role of chaotic dynamics and flow fields in the development of desiquilibrium textures in volcanic rocks. J. Petrol., 44(4):733-756.

Porcher, C.A. \& Lopes, R.C. 2000. Programa Levantamentos Geológicos Básicos do Brasil-Cachoeira do Sul (folha SH.22 Y-A), CPRM/DNPM, (CD-room).

Remus, M. V. D., Hartmann, L. A., McNaugton, N. J., Groves, D. I., Reischl, J. L., 2000. Distal magmatic-hydrothermal origin for the Camaquã $\mathrm{Cu}(\mathrm{Au}-\mathrm{Ag})$ and Santa Maria $\mathrm{Pb}, \mathrm{Zn}(\mathrm{Cu}-\mathrm{Ag})$ deposits, southern Brazil. Gond. Res. 3(2), 155-174.

Righter, K.\& Carmichael, I.A.S. 1996. Phase equilibria of phlogopite lamprophyres from western Mexico: biotite-liquid equilibria and P-T estimates for biotite-bearing igneous rocks. Contrib. Mineral. Petrol, 123:1-21

Rock, N.M.S. 1990. The International Mineralogical Association (IMA/ CNMMN) pyroxene nomenclature scheme: computerization and its consequences. Mineral. Petrol., 43: 99-119.

Rock, N.M.S. 1991. Lamprophyres. $1^{a}$ Ed., Blackie \& Son, Edinburgh, $285 p$.

Rodrigues, E. M. S. 1992. Implantação do método de datação Pb-Pb em rochas totais. Exemplos de aplicação em rochas da Provincia Mineral de Carajás. Dissertação de Mestrado, Centro de Geociências,Universidade Federal do Pará, 128p

Roeder, P.L. \& Emslie, R.F. 1970. Olivine-liquid equilibria. Contrib. Mineral. Petrol., 29:275-289.

Rollinson, H.R., 1993. Using Geochemical Data: Evaluation, Presentation, Interpretation. Longman Sci. Techn., New York, 352p.

Soliani Jr., E. 1986. Os dados Geocronológicos do Escudo Sul-rio-grandense e suas Implicações de Ordem Geotectônica. Tese de Doutorado, Instituto de Geociências, Universidade de São Paulo, 340p.

Stussi, J.M. \& Cuney, M. 1996. Nature of biotites from alkaline, calcalkaline and peraluminous magmas by Abdel-Fattah M. AbdelRahman: A comment. J. Petrol., 37(5): 1025-1029.

Toplis, M.J. \& Carroll, M.R. 1995. An experimental study of the influence of oxygen fugacity on $\mathrm{Fe}-\mathrm{Ti}$ oxide stability, phase relations, and mineral-melt equilibria in ferro-basaltic systems. $J . P e-$ trol., 36:1137-1170.

Watson, E. B. \& Harrison, T.M.1983. Zircon saturation revisited: temperature and composition effects in a variety of crustal magma types. Earth Planet. Sci. Letters, 64:295-304.

Wang, R. -C., Wang, D. -Z., Zhao, G. -T., Lu, J. -J., Chen, X. -M., Xu, $S .-J .2001$. Acessory mineral record of magma-fluid interaction in the Laoshan I- and A-type granitic complex, Eastern China. Phys. Chem. Earth (A), 26(9-10):835-849.

Wass, J. Y. 1979. Multiple origins of clinopyroxenes in alkalic basaltic rocks. Lithos, 12:115-132.

Winchester, J.A. \& Floyd, P.A. 1977. Geochemical discrimination of different magma series and their differentiation products using immobile elements. Chem. Geol., 20: 325-343.

Manuscrito A-1605 Revisão aceita em 25 de julho de 2006 
Reinterpretação do complexo intrusivo Lavras do Sul, RS, de acordo com os sistemas vulcano-plutônicos de subsidência. Parte 2: quimica mineral, geoquímica e isótopos de Pb-Sr-Nd. 